HID 40 (2013)

\title{
EL ARZOBISPADO DE SEVILLA Y EL OBISPADO DE CÁDIZ. IMAGEN DE UN GRAN PARTIDO FISCAL EN LA RECAUDACIÓN DEL PEDIDO REGIO ${ }^{1}$.
}

\author{
THE ARCHBISHOPRIC OF SEVILLE AND THE BISHOPRIC OF \\ CADIZ. IMAGE OF A BIG TAX TERRITORY IN THE COLLECTION \\ OF THE ROYAL "PEDIDO”.
}

\author{
José Manuel Triano Milán². \\ Universidad de Málaga \\ j.m.triano@hotmail.com
}

RESUMEN: El presente artículo estudia la imagen de la geografía fiscal del Arzobispado de Sevilla y el Obispado de Cádiz en vinculación a la recaudación del pedido regio. En relación a este asunto, estudiaremos aspectos como la organización del espacio fiscal o los niveles contributivos de las distintas zonas. Pretendemos, así, aportar una visión general del que fue el partido más destacado en la contribución de uno de los subsidios más importantes de la Corona.

PAlabras Clave: Sevilla, Cádiz, geografía. fiscalidad, Cortes.

ABSTRACT: This article examines the image of the fiscal geography of the Archbishopric of Seville and the Bishopric of Cadiz in connection of the royal pedido. In relation to this, we explore aspects like the organization of the fiscal space and the contributions of the different areas of this territory. We hope to provide a overview of the most prominent "partido" in the contribution of one of the most important taxes of the Crown.

KEYwORDS: Seville, Cadiz, geography, fiscality, parliament.

1. Este trabajo es producto de las investigaciones del autor en el marco de la tesis que realiza bajo la dirección del profesor Ángel Galán Sánchez. La misma es parte del proyecto de investigación del MICINN "Fiscalidad y sociedad en la Corona de Castilla al sur del Tajo" (HAR 2011-26218), integrado en la red temática de investigación cooperativa Arca Comunis (http://www.arcacomunis.uma.es). Abreviaturas utilizadas AGS= Archivo General de Simancas; AMS= Archivo Municipal de Sevilla; EMR=Escribanía Mayor de Rentas; Pap. May.= Papeles del Mayordomazgo.

2. Hemos de expresar nuestro agradecimiento a Julieta Rodríguez Sarria, cuyo consejo y apoyo han sido inestimables y sin los cuáles la aparición del presente artículo no hubiese sido posible. 


\section{INTRODUCCIÓN}

A lo largo del siglo XV la Corona de Castilla fue desarrollando y consolidando unas estructuras geográfico-administrativas que presentaban una mayor coherencia y uniformidad que las de épocas precedentes ${ }^{3}$. Esta distribución del espacio fue la respuesta a unas acuciantes necesidades organizativas del Estado, entre las que aquellas de carácter fiscal contaron con una especial relevancia. En este sentido, vemos como se afianzó una división hacendística del territorio que permitió a la monarquía determinar el potencial contributivo de cada región y lograr un mayor control sobre el sistema de recaudación ${ }^{4}$ de los diversos subsidios y tributos de los que se nutría la Hacienda castellana. Para lograr estos fines, no obstante, la articulación de la geografía físcal no fue creada siempre ex profeso, sino que, con frecuencia, se recurrió a demarcaciones preexistentes. De esta manera, las diversas regiones fiscales se solapaban y mezclaban con otras de tipo administrativo, jurídico, militar y eclesiástico, creando un complejo entramado difícil de analizar. Y más aún si tenemos en cuenta que no existía una geografía tributaria única para toda Castilla. Así, por ejemplo, la recaudación de los servicios de Cortes presentaba una organización espacial que difería de la de otros ingresos de la Corona (alcabalas, tercias, almojarifazgos, etc.) y de las rentas eclesiásticas ${ }^{5}$.

Si nos centramos en estos servicios de Cortes, veremos que tanto pedidos ${ }^{6}$ como monedas $^{7}$, los dos conceptos que componían este importante ingreso extraordinario en el siglo $\mathrm{XV}^{8}$, se recaudaban en una serie de grandes partidos que tomaban como base una organización eclesiástica del espacio. De hecho, la mayor parte de estos territorios fiscales coincidían con los diversos obispados y ar-

3. F.J. AGUADO GONZÁLEZ. "Fuentes para el estudio de la geografía administrativa y la distribución de la población de la Corona de Castilla en la segunda mitad del siglo XV: las relaciones de pueblos para el cobro del pedido", Anuario de Estudios Medievales, nº 16 (1986), p. 466.

4. M.A. LADERO QUESADA. La Hacienda Real de Castilla (1369-1504). Real Academia de la Historia, Madrid, 2009, pp. 487-488.

5. Así lo señala David Alonso para los servicios de Cortes modernos, una apreciación también válida para los servicios del siglo XV. D. ALONSO GARCÍA. "Crear espacios, cobrar impuestos. Los partidos fiscales de Castilla a principios de la Edad Moderna” en L. SALAS ALMELA. Los ámbitos de la fiscalidad: fronteras, territorios y percepción de tributos en los Imperios ibéricos (siglos XV-XVIII), Instituto de Estudios Fiscales y Universidad de Málaga, Madrid, 2011, p. 43.

6. La más actualizada aproximación al funcionamiento general del pedido la encontramos en J. RODRÍGUEZ SARRIA. “¿Cobrar para el rey? Los pedidos regios: procedimientos y agentes de la recaudación en la Sevilla del siglo XV” en A. GALÁN SÁNCHEZ, y E. GARCÍA FERNÁNDEZ. (eds.) En busca de Zaqueo: los recaudadores de impuestos en las épocas medieval y moderna. Instituto de Estudios Fiscales y Universidad de Málaga, Madrid, 2012.

7. La geografía fiscal del servicio parece ser similar tanto para monedas como para pedidos, los dos conceptos en los que se articulaban los servicios de Cortes. Al menos así parece mostrarlo la información que hemos consultado en el Archivo Municipal de Sevilla y el Archivo General de Simancas. No obstante, conocemos el caso de algunos años en el que los territorios fiscales no coinciden exactamente, por lo que creemos conveniente profundizar más en este aspecto antes de aportar una conclusión en este sentido.

8. M.A. LADERO QUESADA. La Hacienda Real... pp. 201 y ss. 
cedianatos $^{9}$ de la Corona. Sólo las merindades de Castilla, las sacadas de Toro, Cáceres, Coria y Asturias de Oviedo, y el Infantado de Valladolid ${ }^{10}$ presentaban una estructura organizativa diferente ${ }^{11}$. Estas antiguas formas de articulación del espacio habían logrado resistir el paso del tiempo y se caracterizaban por identificarse mucho mejor con las realidades regionales e históricas de las zonas a las que organizaban ${ }^{12}$ que los territorios eclesiásticos ya citados.

Tal y como señala el profesor Carretero, para entender toda esta compleja organización del espacio tributario de los servicios hay que tener en cuenta que la misma era el producto de complicados equilibrios del reparto de beneficios entre los procuradores de Cortes $^{13}$. Una comisión de éstos solía ser la que se encargaba de establecer sobre que territorios ejercía su control cada ciudad con voto en esta institución, buscando conseguir un reparto equitativo ${ }^{14}$. Pero ello daba lugar a articulaciones territoriales que en ocasiones resultaban poco lógicas. Así se refleja, por ejemplo, en la dependencia que los territorios del reino de Galicia tenían con respecto a los procuradores de otras regiones ajenas al mismo ${ }^{15}$, circunstancia que fue utilizada por esta zona como una excusa para defender la constante resistencia al pago del pedido ${ }^{16}$ que mantuvo a lo largo del siglo $\mathrm{XV}^{17}$.

Todo ello favoreció, además, que la organización territorial para la recaudación del pedido y las monedas experimentara importantes transformaciones a lo largo de esta centuria. Así, resulta muy difícil encontrar dos relaciones de partidos que coincidan con exactitud, siendo frecuente que éstos se uniesen o separasen en la contribución ${ }^{18}$.

9. M.A. LADERO QUESADA. "Las regiones históricas y su articulación política en la Corona de Castilla durante la Baja Edad Media”, En la España Medieval, nº 15, pp. 214-215.

10. Sobre la recaudación del servicio en éste último territorio contamos con la clarificadora descripción de C. OLIVERA SERRANO. "Pedidos y monedas en Valladolid y su infantado a mediados del siglo XV", en Valladolid: historia de una ciudad. Congreso internacional. Tomo I: La ciudad medieval y el arte, Ayuntamiento de Valladolid, Valladolid, 1999, pp. 316 y ss.

11. J.M. CARRETERO ZAMORA La averiguación de la Corona de Castillla (1525-1540). Los pecheros y el dinero del reino en la época de Carlos $V$ vol. I, Junta de Castilla y León, Salamanca, pp. 96-97.

12. M.A. LADERO QUESADA. "Las regiones históricas...”, p. 217.

13. J.M. CARRETERO ZAMORA. La averiguación ... vol I, p. 101.

14. Ibid.

15. La designación de a qué procuradores correspondía cada partido queda reflejada en los documentos de concesión del servicio, que para el período de 1445-1474 fueron publicados por C. OLIVERA SERRANO. Las Cortes de Castilla y León y la crisis del reino. El registro de Cortes, vol. II, Cortes de Castilla y León, Burgos, 1986.

16. Los territorios gallegos contaban con una exención general para el pago de las monedas, por lo que el único concepto a cuyo pago tenían que hacer frente en los servicios de Cortes era al pedido. C. OLIVERA SERRANO. "El pedido de 1455 en el reino de Galicia", Cuaderno de Estudios Gallegos, tomo LI, fascículo 117, 2004, p. 366.

17. Sobre esta resistencia y las vicisitudes del pago del pedido en general a lo largo del siglo XV en Galicia consúltese A. RUBIO MARTÍNEZ. "Los ingresos extraordinarios del reino de Galicia en el siglo XV”, Cuadernos de Estudios Gallegos, tomo 57, n 123 (2010), pp. 229-271.

18. Pese a ello, un vistazo a una de estas listas permite hacerse una idea aproximada de cuáles eran estos grandes partidos. Véase cuadro 1 del Anexo. 
Cada uno de estos partidos estaba compuesto, a su vez, por una serie de unidades fiscales. Lo más habitual es que éstas se identifiquen con diversos concejos y los términos dependientes de éstos, especialmente en los territorios al sur del Tajo. Pero, en las relaciones con las que contamos para algunos de estos partidos, podemos observar como aparecen también otro tipo de poblaciones como villas, monasterios, feligresías, etc ${ }^{19}$. Las instituciones responsables de estas unidades fiscales solían ser las que, en teoría, se encargaban de organizar la recaudación del pedido en su territorio. Al menos, esta es la imagen tradicional que se ha transmitido sobre el funcionamiento de este subsidio, pero todo parece indicar que la situación no era tan simple, y que, en realidad, variaba según la región de la que estemos hablando. Así, conocemos ejemplos de lugares donde esta ayuda era arrendada, como ocurría con otros ingresos de la Corona ${ }^{20}$.

Tal y como indicábamos, se presenta ante nosotros una situación muy compleja, que requiere un estudio en profundidad en todo el territorio castellano. Pese a ello, el objetivo del presente artículo es mucho más modesto, pues nos centraremos únicamente en mostrar una imagen general de uno de estos grandes partidos, el del Arzobispado de Sevilla y el Obispado de Cádiz. La elección de este territorio viene determinada por diversas circunstancias. En primer lugar, se trata del partido que más solía contribuir en este subsidio de entre todos los de la Corona, contando en su seno, además, con la unidad fiscal que más aportaba al pedido, la de la ciudad de Sevilla y su tierra. A ello hay que añadir que es una de las zonas mejor documentadas de toda Castilla, gracias a las abundantes noticias que en torno a este asunto se contienen en los libros de pedido que se han conservado en el Archivo Municipal hispalense ${ }^{21}$. Allí, además de encontrar información de esta ayuda en la ciudad y su alfoz, el investigador puede hallar información inestimable sobre el pago de este subsidio en todo el Arzobispado de Sevilla y el Obispado de Cádiz.

\section{El Arzobispado de Sevilla y el Obispado de Cádiz. Una imagen GENERAL}

El Arzobispado de Sevilla y el Obispado de Cádiz era un gran partido fiscal que englobaba un vasto territorio que comprendía las actuales provincias de Huelva, Cádiz y Sevilla, así como parte de la actual provincia de Badajoz y de la

19. Por suerte, contamos con una completa imagen de estas poblaciones en la única relación del pago del pedido que conocemos para toda la Corona, la del año 1455. AGS, EMR, Leg. 1, fols 455r-604r. Para una aproximación al estudio de este documento véase F.J. AGUADO GONZÁLEZ. "Fuentes para el estudio...".

20. Este parece ser el caso de ciertos territorios del reino de Galicia, según indica C. OLIVERA SERRANO. "El pedido de $1455 \ldots .$, , p. 366.

21. Concretamente en la sección 15 del mismo. Se trata de una serie documental única, ya que no conocemos otra que nos ofrezca noticias tan abundantes sobre este subsidio por el momento. Así lo indicó el profesor Collantes de Terán en la introducción del estudio de F.J. ROMERO ROMERO. Sevilla y los pedidos de Cortes en el siglo XV, Ayuntamiento de Sevilla, Sevilla, 1997, p. 12. 
de Málaga (Antequera) ${ }^{22}$. Esta zona se encontraba dividida, a su vez, en cuatro subpartidos más pequeños: el de Sevilla, el de Jerez, el de Écija y el de Niebla ${ }^{23}$. En el seno de cada uno de ellos se encontraban una serie de unidades fiscales que contribuían en el pedido, cuyo tamaño e importancia eran muy desiguales entre si.

La organización del espacio de dicho partido permaneció casi inalterable, al menos desde 1411, momento en el que se inician las relaciones con las que contamos para el mismo ${ }^{24}$, hasta 1478 , cuando el pedido fue sustituido por las contribuciones de la Hermandad y fue aprobada una nueva organización territorial ${ }^{25}$ para su recaudación. Sólo contamos con una salvedad a esta tendencia en 1443, cuando se produjeron importantes modificaciones que fueron revocadas casi de inmediato ${ }^{26}$.

Estas unidades fiscales que conformaban cada uno de los subpartidos, a las que hemos hecho referencia, presentaban, a su vez, una serie de subdivisiones internas para facilitar la recaudación de este subsidio, utilizando para ello unidades administrativas preexistentes como concejos, collaciones o barrios. Estas subdivisiones poseían algunas particularidades que influían en todo este proceso, al tiempo que experimentaron una evolución con el paso del tiempo que no puede dejar de ser tenida en cuenta.

Para lograr una mayor comprensión de estos aspectos, creemos necesario presentar un análisis de la organización interna de cada uno de estos subpartidos. En dicho análisis, tendremos en cuenta que zonas se encuentran bajo dominio real y cuáles bajo jurisdicción señorial. Un aspecto que, además de facilitar el proceso descriptivo que vamos a emprender, presenta un gran interés por el importante impacto que tuvo sobre el proceso de recaudación del pedido, como mostraremos más adelante.

\section{La Joya del Arzobispado. El subpartido de Sevilla}

Sin duda alguna, el subpartido más importante dentro de todo el Arzobispado de Sevilla y el Obispado de Cádiz era el conformado por la ciudad hispalense, su

22. J.M. CARRETERO ZAMORA. La averiguación ... vol I, p. 101.

23. Así lo muestran los repartimientos con los que contamos para este gran partido fiscal. Véase tabla 2 del Anexo.

24. Disponemos de otras relaciones anteriores del Arzobispado bastante incompletas, como la de 1408. (AMS, Pap. May., Rollo 204, 1408). Cabe preguntarse si la misma se ha llegado hasta nosotros de esta manera por haberse conservado de manera fragmentaria o porque la geografía físcal de este nuevo subsidio (el pedido había sido recuperado en 1406 como concepto recaudatorio) aún estaba en proceso de conformación. Aspecto éste que merece un análisis más detallado en un futuro cercano y que, quizás, nos ayude a comprender mejor el tema que aquí tratamos.

25. Para esta nueva organización territorial de la Hermandad véase J.M. CARRETERO ZAMORA. La averiguación ... vol. I, pp. 102-105.

26. Este año fue nombrado un recaudador mayor independiente para el subpartido de Écija, que pasó a englobar, además, las Sierras de Aroche y Constantina, que eran parte del alfoz de la ciudad de Sevilla. Las causas que determinaron esta situación aún no han podido ser esclarecidas con la documentación de la que disponemos. AMS, Pap. May., Rollo 260, Caja 43, Pedido de 1443. 
alfoz dependiente y los territorios de señorío enclavados en su interior. Dentro del mismo, podemos observar como la mayor parte de la carga de la recaudación era asumida por Sevilla y su tierra, que era la unidad fiscal más importante de toda la Corona en la contribución del pedido ${ }^{27}$. El gran dinamismo económico de la ciudad del Betis, unido a su poderío demográfico ${ }^{28}$ y a la amplitud de su alfoz dependiente, permiten entender esta situación.

Junto a estos importantes territorios de realengo, que abarcaban la mayor parte del espacio y de la población de este subpartido, existían una serie de dominios señoriales, rodeados por territorios pertenecientes a la ciudad hispalense como si de pequeñas islas se tratasen. Pese a ello, mantuvieron su independencia en el pago del pedido, no quedando supeditados nunca al concejo de Sevilla.

\section{Sevilla y su tierra}

El territorio de realengo del subpartido de Sevilla estaba conformado por la capital hispalense y su alfoz, un rico y vasto territorio ${ }^{29}$ sobre el que este concejo ejercía un control directo desde un punto de vista político, económico y también fiscal ${ }^{30}$. Dicha tierra se encontraba subdividida en cuatro grandes comarcas para facilitar el proceso de recaudación cuyos nombres han llegado hasta la actuali$\operatorname{dad}^{31}$ : Campiña, Aljarafe y Ribera, Sierra de Constantina y Sierra de Aroche. Cada una de ellas contaba con unas características propias que las distinguía de las demás y que acabaron influyendo en la recaudación del pedido.

La Sierra era un lugar altamente poblado en esta época si lo comparamos con las otras comarcas del alfoz hispalense ${ }^{32}$. Se encontraba dividida en dos regiones, Aroche, de mayor importancia, mucho más extensa y con mayor densidad de población, y la Sierra de Constantina, más pequeña y con un menor número

27. Así nos lo muestra la relación del pedido de 1455, a la que ya hicimos mención (AGS, EMR, Leg. 1, ff. 455r-604r). Para un ejemplo de las importantes cifras de contribución de esta población véase la tabla 2 del Anexo.

28. Un análisis demográfico detallado de la ciudad lo encontramos en el ya clásico estudio de A. COLLANTES DE TERÁN SÁNCHEZ. Sevilla en la Baja Edad Media. La ciudad y sus hombres, Ayuntamiento de Sevilla, Sevilla, pp. 133-219. Para la tierra podemos consultar los datos de diversos estudios recogidos en C. FLORES VARELA. Estudio demográfico de la Andalucía cristiana, 14001535, Tesis doctoral dirigida por Cristina Segura Graiño, Universidad Complutense de Madrid, 2001.

29. El profesor Ladero señala que éste territorio ocupaba unos $12.000 \mathrm{~km}^{2}$. El mismo, además, no se vio reducido por procesos de señorialización, a diferencia de lo que ocurrió con otros territorios de realengo del Arzobispado de Sevilla y el Obispado de Cádiz en esta época. M.A. LADERO QUESADA. Historia de Sevilla. La ciudad medieval (1248-1492), Universidad de Sevilla, Sevilla, 1989, pp. 72 y ss.

30. J.M. NAVARRO SAÍNZ. "La subordinación política de la tierra de Sevilla al concejo hispalense en el reinado de Isabel I", Historia, instituciones, documentos, $\mathrm{n}^{\circ} 38$, (2011), pp. 327-328.

31. M.A. LADERO QUESADA. Historia de Sevilla... p. 73

32. Así, datos con los que contamos nos muestran cómo la capacidad demográfica de la zona superaba ampliamente a la del Aljarafe durante la primera mitad del siglo, situación que se acentuó más aún en la segunda mitad del mismo. No contamos, no obstante, con una comparación similar con la zona de la Campiña, M. BORRERO FERNÁNDEZ. "Situación demográfica de la Sierra Norte de Sevilla (siglo XV-1534)", Historia, instituciones, documentos, no 25 (1998), p. 58. 
de concejos $^{33}$. Ambas presentaban una economía propiamente serrana ${ }^{34}$, lo que las alejaría de la importancia económica que llegarían a adquirir la Campiña y, sobre todo, el Aljarafe. Además, pese a esa elevada población a la que hacíamos referencia anteriormente vemos como, en el caso de Aroche, la inseguridad fue un problema crónico a lo largo de toda esta etapa, lo que seguramente acabó favoreciendo una situación de inestabilidad en el poblamiento que contrasta con las de otras regiones del alfoz sevillano ${ }^{35}$.

La Campiña, por su parte, sufrió el hecho de que parte de su territorio, el que formaba parte de la llamada "banda morisca", se encontrara expuesta a las constantes agresiones procedentes desde Granada ${ }^{36}$. No obstante, con el paso del tiempo, cuando estas agresiones fueron decreciendo, se fue convirtiendo en una próspera región cerealera ${ }^{37}$. Una prosperidad que quedó reflejada en el hecho de que, si bien poco numerosos, los concejos situados en su interior contaran con una gran importancia demográfica y económica ${ }^{38}$.

Por último, el Aljarafe y la Ribera es, quizás, la más conocida de estas regiones. Ésta se caracterizaba por la gran cantidad de núcleos de población existentes en su interior, aunque ninguno alcanzó la importancia demográfica de los principales concejos de las Sierras y la Campiña. Pese a ello, vemos que si durante la primera mitad del siglo el Aljarafe aún no era una zona especialmente relevante y se veía superada en importancia por otras comarcas, a partir de mediados de siglo inició el despegue que lo convertiría en el territorio más rico del alfoz ${ }^{39}$. Una prosperidad sostenida, fundamentalmente, sobre el cultivo del olivo. Todo ello favoreció que fuese aquí donde las élites de la ciudad concentrasen sus propiedades ${ }^{40}$ y se conformasen la mayor parte de los señoríos de los que hablaremos más adelante.

Dentro de estas comarcas no todos los núcleos de población pagaban, ya que algunos de ellos contaban con exenciones, que podían haber recibido tanto del mismo monarca como del Concejo de la ciudad ${ }^{41}$. Los concejos con una de estas franquezas permanentes no solían aparecer reflejados en los repartimientos, por lo que se podría decir que no formaban parte de la geografía fiscal del servicio. La relación general de los que sí lo hacían, o tenemos constancia de que lo hicieron en algún momento, es la siguiente:

33. M.A. LADERO QUESADA. Historia de Sevilla ... pp. 72 y ss.

34. M. BORRERO FERNÁNDEZ. "Situación demográfica..." p. 45.

35. M. BORRERO FERNÁNDEZ. "Situación demográfica...” p. 55.

36. M.A. LADERO QUESADA. Historia de Sevilla ... p. 78.

37. Ibid.

38. C. FLORES VARELA. Estudio demográfico... pp. 458-459.

39. M. BORRERO FERNÁNDEZ. El mundo rural sevillano en el siglo XV: Aljarafe y Ribera. Diputación provincial de Sevilla, Sevilla, 1983, pp. 189 y ss.

40. M. BORRERO FERNÁNDEZ. El mundo rural... p. 280.

41. F.J. ROMERO ROMERO. Sevilla y los pedidos... pp. 20-21. 
Tabla 1. Distritos fiscales de la tierra de Sevilla ${ }^{42}$

\begin{tabular}{|c|c|}
\hline Comarca & Distrito fiscal \\
\hline Sierra de Aroche & Fregenal de la Sierra \\
\hline Sierra de Aroche & Aroche \\
\hline Sierra de Aroche & Aracena \\
\hline Sierra de Aroche & Santa Olalla \\
\hline Sierra de Aroche & Zufre \\
\hline Sierra de Aroche & Encina Sola \\
\hline Sierra de Aroche & La Marotera \\
\hline Sierra de Aroche & Cumbres Mayores \\
\hline Sierra de Aroche & El Bodonal \\
\hline Sierra de Aroche & Cortegana \\
\hline Sierra de Aroche & La Higuera \\
\hline Sierra de Aroche & Cala \\
\hline Sierra de Aroche & Cumbres de San Bartolomé \\
\hline Sierra de Aroche & El Cerro \\
\hline Sierra de Aroche & Real \\
\hline Sierra de Aroche & Castilblanco \\
\hline Sierra de Aroche & Almadén \\
\hline Sierra de Aroche & Castillo de las Guardas \\
\hline Sierra de Constantina & Alanís \\
\hline Sierra de Constantina & Cazalla de la Sierra \\
\hline Sierra de Constantina & Constantina \\
\hline Sierra de Constantina & El Pedroso \\
\hline Sierra de Constantina & La Puebla del Infante \\
\hline Sierra de Constantina & Villanueva del Camino \\
\hline Sierra de Constantina & San Nicolás del Puerto \\
\hline La Campiña & Utrera \\
\hline La Campiña & Lebrija \\
\hline La Campiña & Alcalá de Guadaira \\
\hline La Campiña & Dos Hermanas \\
\hline La Campiña & Las Cabezas de San Juan. \\
\hline Aljarafe y Ribera & Hinojos \\
\hline Aljarafe y Ribera & Aználcazar \\
\hline Aljarafe y Ribera & Villa de Sanlúcar la Mayor \\
\hline Aljarafe y Ribera & Alcalá del Río \\
\hline Aljarafe y Ribera & Escacena \\
\hline Aljarafe y Ribera & Gerena \\
\hline Aljarafe y Ribera & Manzanilla \\
\hline Aljarafe y Ribera & Paterna \\
\hline
\end{tabular}

42. La siguiente relación de distritos fiscales ha sido establecida en base a diversos repartimientos que hemos podido encontrar en los libros de pedido de la sección XV del Archivo Municipal de Sevilla. 


\begin{tabular}{|c|c|}
\hline Aljarafe y Ribera & Salteras \\
\hline Aljarafe y Ribera & Huévar \\
\hline Aljarafe y Ribera & Coria \\
\hline Aljarafe y Ribera & Aznalcóllar \\
\hline Aljarafe y Ribera & La Puebla \\
\hline Aljarafe y Ribera & Castilleja del Campo \\
\hline Aljarafe y Ribera & La Rinconada \\
\hline Aljarafe y Ribera & Pilas \\
\hline Aljarafe y Ribera & Chillas \\
\hline Aljarafe y Ribera & Guillena \\
\hline Aljarafe y Ribera & Tejada \\
\hline Aljarafe y Ribera & Burguillos \\
\hline Aljarafe y Ribera & Camas \\
\hline Aljarafe y Ribera & Mitación* de Bollullos \\
\hline Aljarafe y Ribera & Mitación de Santo Domingo \\
\hline Aljarafe y Ribera & Mitación de San Juan de Aznalfarache. \\
\hline Aljarafe y Ribera & Mitación de Palomares. \\
\hline Aljarafe y Ribera & Mitación de Valencina del Alcor. Cazalla de Almanzor. \\
\hline Aljarafe y Ribera &
\end{tabular}

* Las mitaciones eran pequeñas unidades jurisdiccionales que mantenían en su territorio varios núcleos de población, actuando uno de ellos como cabeza de mitación. M. BORRERO FERNÁNDEZ, El mundo rural..., pp. 180 y ss.

Todo este inmenso territorio sobre el que Sevilla mantenía el control, unido a la ya señalada importancia demográfica y económica de esta plaza, le permitía mantener unos niveles de contribución muy alejados de los que cualquier otro territorio en el Arzobispado pudiera alcanzar. De hecho, a lo largo de los años para los que tenemos información ${ }^{43}$ podemos comprobar como esta unidad fiscal supuso siempre más de la mitad (en torno al 51\%) del pago del pedido del mismo. Este predominio se hace aún más evidente dentro del denominado subpartido de Sevilla, en el que la ciudad hispalense y su alfoz contribuyeron siempre con más del $87 \%$ del total.

\section{Los territorios de señorío del subpartido de Sevilla}

La importancia de Sevilla y su tierra no puede hacernos olvidar que también existían en este subpartido una serie de territorios señoriales que contribuían al pago del pedido. La mayor parte de éstos se encontraban situados en la comarca del Aljarafe y Ribera, aunque existen excepciones ${ }^{44}$. Pese a ser bastante numero-

43. Véase Anexo.

44. Ejemplo de ello son las localidades de Zalamea y Almonaster, localizadas en el Andévalo y la sierra de Aroche, o las de Gandul y Marchenilla, enclavadas en la comarca de la Campiña. 
sos, la escasa entidad territorial que poseyeron y la alta capacidad de resistencia de Sevilla frente a los intentos expansivos de los mismos llevó a que la mayor parte de esta zona se mantuviese bajo control real. Una situación que continuó a lo largo del siglo, pese al avance generalizado que experimentaron las tierras de señorío en el Arzobispado de Sevilla y el Obispado de Cádiz ${ }^{45}$. Así, a comienzos del quinientos, vemos como un $74 \%$ de este subpartido era aún territorio de realengo ${ }^{46}$.

Tabla 2. Señoríos que contribuyen al pedido en el subpartido de Sevilla ${ }^{47}$

\begin{tabular}{|c|c|c|}
\hline Señorío & Tipo & Titular \\
\hline Cantillana & Eclesiástico & Arzobispo de Sevilla \\
\hline Brenes & Eclesiástico & Arzobispo de Sevilla \\
\hline Rianzuela & Eclesiástico & Arzobispo de Sevilla \\
\hline $\begin{array}{l}\text { Umbrete (con Aguazul } \\
\text { y Aguazulejo) }\end{array}$ & Eclesiástico & Arzobispo de Sevilla \\
\hline Zalamea & Eclesiástico & Arzobispo de Sevilla \\
\hline Almonaster & Eclesiástico & Arzobispo de Sevilla \\
\hline Villaverde & Eclesiástico & Arzobispo de Sevilla \\
\hline La Albaida & Eclesiástico & Cabildo catedralicio \\
\hline Robaina & Eclesiástico & Orden de San Juan \\
\hline Carrión de los Ajos & Eclesiástico & Orden de Calatrava \\
\hline Castilleja de la Cuesta & Eclesiástico & Orden de Santiago \\
\hline Mures & Eclesiástico & Orden de Santiago \\
\hline Villanueva de Aliscar & Eclesiástico & Orden de Santiago \\
\hline Castilleja de Alcántara & Eclesiástico & Orden de Alcántara \\
\hline Caracena & Eclesiástico & Orden de Alcántara \\
\hline Torralba & Eclesiástico & Orden de Alcántara \\
\hline Santiponce & Eclesiástico & Orden Jerónima \\
\hline Gatos & Secular & Juan Sánchez de Sevilla/ familia Stúñiga \\
\hline Purchena & Secular & $\begin{array}{l}\text { Isabel de Castañeda (esposa del conde } \\
\text { de Cifuentes)/Diego de Stúñiga }\end{array}$ \\
\hline Estercolinas & Secular & $\begin{array}{c}\text { Per Afán de Ribera/Juan Pacheco/Conde } \\
\text { de Niebla }\end{array}$ \\
\hline Gandul y Marchenilla & Secular & Familia Velasco \\
\hline Castilleja de Talhara & Secular & Familias Fuentes y Mendoza \\
\hline
\end{tabular}

45. Para un estudio pormenorizado de este aspecto véase A. COLLANTES DE TERÁN SÁNCHEZ. "Los señoríos andaluces. Análisis de su evolución territorial en la Edad Media", Historia, instituciones, documentos, $\mathrm{n}^{\circ} 6$ (1979), pp. 89-112.

46. A. HERRERA GARCÍA. El Aljarafe sevillano durante el Antiguo Régimen: un estudio de su evolución socioeconómica, Diputación de Sevilla, Sevilla, 1980, p. 55.

47. La mayor parte de los datos del siguiente cuadro han sido extraídos de M. BORRERO FERNÁNDEZ. El mundo rural... pp. 47 y ss. 


\begin{tabular}{|c|c|c|}
\hline La Algaba & Secular & $\begin{array}{c}\text { Juan de Tovar/ Descendientes de don } \\
\text { Gonzalo de Guzmán/ Pedro Girón/Juan } \\
\text { Téllez Girón }\end{array}$ \\
\hline Gines & Secular & Familia Stúñiga/Alonso Ortiz \\
\hline Gelves & Secular & Familia Tovar \\
\hline Chucena & Secular & $\begin{array}{c}\text { Familias Orellana y Ribera/Familias } \\
\text { Portocarrero y Ribera }\end{array}$ \\
\hline
\end{tabular}

Estos dominios señoriales no presentan una imagen homogénea, sino que muestran importantes diferencias en su conformación y evolución según pertenecieran a la Iglesia sevillana o a miembros del estamento nobiliario. Es por ello que distinguiremos entre ambos tipos de señorío en nuestro análisis.

\section{Señoríos eclesiásticos}

Los señoríos vinculados a la Iglesia se caracterizan por tener su origen en la época del repartimiento o momentos inmediatamente posteriores a éste. Fueron, en su mayoría, donaciones reales a las diversas instituciones eclesiásticas del recién conformado Arzobispado de Sevilla ${ }^{48}$. Dentro de las mismas podemos distinguir entre las posesiones del Arzobispo, las del Cabildo Catedralicio, las de las órdenes militares y la de las órdenes monásticas.

En el caso del Arzobispo de Sevilla, vemos como ejerció el dominio jurisdiccional sobre algunas de las plazas con mayor importancia contributiva de este subpartido. Especial mención merece Cantillana, el concejo más importante de la zona de la Ribera y la segunda población que más contribuía en el subpartido de Sevilla, tras la capital hispalense ${ }^{49}$. No obstante, este hecho no ha de hacernos olvidar que su importancia total dentro del Arzobispado era bastante modesta, como muestran sus niveles de contribución (en torno al 0,79\% del total). Aspecto éste que nos hace ver, una vez más, la escasa importancia de los núcleos que no pertenecen al realengo en este subpartido.

A todas estas posesiones, situadas en su mayor parte en la zona del Aljarafe y Ribera, hay que añadir también aquellas situadas en la zona serrana de la actual provincia de Huelva, como Zalamea y Almonaster. Éstas, si bien en un principio pertenecieron a la ciudad de Sevilla, acabaron siendo cedidas al Arzobispo a cambio de la Puebla de Cazalla ${ }^{50}$.

Junto a estos dominios, el Cabildo Catedralicio también ejerció la jurisdicción de algunos concejos, aunque sus dominios abarcaban muchos menos unidades

48. M. BORRERO FERNÁNDEZ. El mundo rural... pp. 55-56.

49. Véase Anexo.

50. J. PÉREZ-EMBID WAMBA. "Las sierras de Aroche y Aracena: la formación de una unidad comarcal en el reino de Sevilla durante la Baja Edad Media”, en J.L. CARRIAZO RUBIO y J.M. MIURA ANDRADES. (coord.); Huelva en la Edad Media 20 años después, Universidad de Huelva, Huelva, 1998, p. 113. 
fiscales que los del Arzobispo. Además, estas posesiones se irían reduciendo sensiblemente con el paso del tiempo. De esta forma, señoríos como Chillas y Gatos, que habían pertenecido a estas instituciones en el siglo XIV, fueron vendidos posteriormente, al considerarse que resultaban poco rentables ${ }^{51}$. Así, en la época que aquí estudiamos, sólo podemos hacer mención al señorío de la Albaida en este sentido.

Más numerosos eran los dominios que las órdenes militares poseían en el subpartido de Sevilla. Éstos habían pasado a sus manos como consecuencia de su importante participación en la toma de la ciudad, con el objetivo de premiarlas por su apoyo y establecer unas bases defensivas sólidas ante posibles contraataques musulmanes. No obstante, aunque todas las grandes órdenes militares estarán presentes en territorio sevillano ${ }^{52}$, dicha presencia no será igual para todas. Un simple vistazo al cuadro anterior nos permitirá apreciar cómo los importantes dominios de órdenes como la de Calatrava o Santiago contrastan con las reducidas posesiones de las órdenes de San Juan y de Alcántara.

Por último, no podemos dejar de hacer una breve mención a las propiedades de órdenes religiosas en este subpartido aunque éstas, en realidad, brillen más bien por su ausencia. De hecho, el único caso que conocemos es el de Santiponce, que se encontraba bajo la autoridad de la orden jerónima ${ }^{53}$. Si bien otras órdenes poseían importantes propiedades en esta zona, no conocemos ningún otro caso en el que llegaran a ejercer su dominio sobre una de las poblaciones que pagaban el pedido.

\section{Señoríos seculares}

Junto a estos territorios de dominio eclesiástico de los que hemos hablado hasta ahora existían numerosos señoríos seculares en este subpartido. Éstos inician su formación de manera más tardía y experimentan frecuentes cambios en su titularidad y configuración a lo largo del período que aquí estudiamos. Presentan, por tanto, una imagen bastante diferente de la de los estables territorios bajo jurisdicción eclesiástica. En realidad, pocos aspectos comparten con éstos, salvo su pequeño tamaño y su bajo nivel contributivo.

El más grande de todos ellos era Estercolinas (Olivares), que pasó de formar parte de los dominios del mayorazgo de Per Afán de Ribera a principios de la centuria, a las manos del marqués de Villena, que lo adquirió por compra a mediados de siglo. Tras la caída en desgracia de Juan Pacheco parece que la posesión del mismo quedó en manos del conde de Niebla ${ }^{54}$.

51. M. BORRERO FERNÁNDEZ. El mundo rural... pp. 35-36.

52. La orden del Temple también estaría presente en el Arzobispado, con el dominio de plazas como la de Fregenal de la Sierra, que posteriormente pasaría a pertenecer a la ciudad de Sevilla. R. CARANDE Y THOVAR. Sevilla, fortaleza y mercado: las tierras, las gentes y la administración de la ciudad en el siglo XIV, Diputación provincial de Sevilla, Sevilla, 1982, p. 97.

53. A. COLLANTES DE TERÁN SÁNCHEZ. "Los señoríos andaluces...,", p. 96.

54. A. HERRERA GARCÍA. El Aljarafe... p. 58. 
El señorío de Gatos, como indicamos, perteneció al Cabildo de la Catedral de Sevilla hasta su venta a finales del siglo XIV. Tras esto pasó a manos de Juan Sánchez de Sevilla, contador del rey, que a su vez lo vendió a don Diego López de Stuñiga, quedando en manos de esta importante familia lo que quedaba de siglo. A este linaje perteneció también el señorío de Purchena, aunque la titularidad no fue única, sino compartida con otras familias. Aunque la importancia económica y demográfica de esta localidad no dejó de decaer a lo largo de esta etapa hasta el punto que a finales de siglo era uno de los despoblados del territorio aljarafeño ${ }^{55}$.

Las plazas de Gandul y Marchenilla, por su parte, pese a las quejas del Concejo de Sevilla, que consideraba que les pertenecía legítimamente; fueron adquiridas por la poderosa familia de los Velasco, que las integraron en sus estados.

Mayores dificultades encontramos a la hora de distinguir la titularidad de los señoríos de Gelves, La Algaba y Gines, que experimentan cierta inestabilidad en este sentido a lo largo del siglo $\mathrm{XV}^{56}$. Una situación compleja presenta también Castilleja de Talhara, cuyo dominio fue compartido por los Fuentes y los Mendoza ${ }^{57}$.

\section{El subpartido de Jerez de la Frontera}

Una imagen muy diferente a la del territorio dominado por la ciudad hispalense presenta el subpartido de Jerez de la Frontera. Si bien en aquel toda la articulación territorial quedaba marcada por la presencia de un importante concejo de realengo que eclipsaba a los territorios de señorío, en la zona jerezana nos encontramos con una situación muy distinta. Aquí, la cabeza de esta región fiscal, pese a contribuir más que ninguna otra población, no presenta una importancia similar a la de Sevilla en su subpartido (Jerez supone en torno al 46\% del mismo frente al $87 \%$ de Sevilla $\left.{ }^{58}\right)$. Otra diferencia es la existencia otros grandes concejos, que compiten con Jerez en importancia económica, demográfica y contributiva. Este es el caso de las ciudades de Sanlúcar de Barrameda y el Puerto de Santa María, bajo dominio señorial. Por tanto, el predominio de los territorios de realengo no fue tan relevante en este subpartido como lo era en el de Sevilla. Una situación que se acentuó con el paso del tiempo, dando lugar a que a finales del siglo XV, salvo unos pocos núcleos, entre los que sobresale la propia Jerez, la mayor parte de ésta región fiscal estuviese ya conformada por territorios de señorío.

55. Así se refleja ya en el pedido de 1462. AGS, EMR, Leg. 10, fols. 100r-101r.

56. Su evolución puede seguirse en M. BORRERO FERNÁNDEZ. El mundo rural... pp. 48 y ss.

57. Este dominio compartido fue extensamente estudiado por A. HERRERA GARCÍA. "Noticias, documentos y vicisitudes de los señoríos de Castilleja de Talhara, despoblado del Aljarafe", Hidalguía, XXVI, nº 146, pp. 65-88.

58. Véase Anexo. 
1. Los territorios de realengo del subpartido de Jerez

La plaza más importante, aquella que daba nombre al subpartido y actuaba como cabeza de éste ${ }^{59}$ era Jerez de la Frontera. Este concejo, aunque lejos del poderío de la ciudad hispalense, tal y como se refleja en su capacidad contributiva en el pedido ${ }^{60}$, logró convertirse en una de las unidades fiscales más importantes de todo el Arzobispado. Dicha relevancia fue la consecuencia directa de su importancia en el abastecimiento de la región y de su importante posición estratégica, que la convirtió en una pieza clave del sistema defensivo de la zona frente a la amenaza musulmana y en un punto destacado de las rutas del comercio internacional ${ }^{61}$. Todo ello permitió que se convirtiese en uno de los pocos enclaves que permitieron limitar el predominio señorial que se fue consolidando en este subpartido y, en general, en toda la Baja Andalucía a lo largo de la Baja Edad Media. ${ }^{62}$

Jerez ejercía su dominio sobre un amplio alfoz, sobre el que poseía un control semejante al que mostraba la ciudad hispalense en los dominios de su tierra. Las similitudes, no obstante, acaban aquí, ya que dicho territorio no puede ser comparado con el de la ciudad de Sevilla, mucho más vasto, rico y poblado ${ }^{63}$. De hecho, a finales de siglo la tierra de Jerez sólo englobaba ya algunas pocas localidades de escasa entidad poblacional tales como Asta, Burujena, Pozuela, Santiago de Fe, La Ina, Albadalejo, Chipipe, Cabeza del Real, Martelilla, Portal y Gigonza ${ }^{64}$. Pese a todo, esta importante región cerealera ${ }^{65}$ permitió mantener, en gran medida, la prosperidad de la ciudad.

Junto a Jerez existieron otros núcleos de realengo de cierta importancia. Este es el caso de Carmona, estratégica plaza situada apenas a unas decenas de kilómetros de la ciudad de Sevilla y una de las más importantes de todo el subpartido. Desde su conquista por Fernando III la ciudad había mantenido su independencia ante el avance señorial, y así se mantendría durante toda la época que aquí estudiamos. No se puede decir lo mismo de Cádiz, pequeña ciudad portuaria prácticamente sin

\section{Ibid.}

60. Jerez, siendo la segunda unidad fiscal que más pagaba de todo el Arzobispado de Sevilla y el Obispado de Cádiz, suponía una cifra en torno al 8\% de la contribución total del subpartido frente al $51 \%$ de Sevilla.

61. Todos estos aspectos ya fueron señalados por el profesor A. COLLANTES DE TERÁN SÁNCHEZ. "Las ciudades andaluzas en la transición de la Edad Media a la Moderna", Minervae Baeticae. Boletín de la Real Academia Sevillana de Buenas Letras, 32 (2004), p. 45.

62. M. GONZÁLEZ JIMÉNEZ. "La Baja Andalucía a fines del medievo", Arquipélago. Revista da Universidade dos Açores. Serie Historia. Vol XI (1989), p. 12.

63. Frente a los $12.000 \mathrm{~km}^{2}$ del alfoz sevillano, el jerezano se extendía por unos $1.393,2 \mathrm{~km}^{2}$. E. MARTÍN GUTIÉRREZ. La identidad rural de Jerez de la Frontera. Territorio y poblamiento durante la Baja Edad Media, Publicaciones de la Universidad de Cádiz, Cádiz, 2003, p.19.

64. E. MARTÍN GUTIÉRREZ. La identidad rural..., p. 160.

65. El profesor González Jiménez estima que a finales de siglo esta región producía el 12\% del trigo de todo el Arzobispado, que exportaba, además, a otras regiones M. GONZÁLEZ JIMÉNEZ. "La Baja Andalucía...", p. 17. 
término propio ${ }^{66}$ que experimentará un breve periodo bajo el dominio señorial del conde de $\operatorname{Arcos}^{67}$.

Como vemos, la importancia del realengo se encontraba en esta zona a bastante distancia de la del subpartido de Sevilla. Ello queda claramente reflejado en la contribución del pedido. Así, vemos como, mientras en el subpartido de Sevilla el pago de los territorios de señorío nunca llegó a alcanzar el 15\% de lo que el total del mismo representaba, en este subpartido las cifras fueron mucho más elevadas $^{68}$. No obstante, gracias a Carmona y Jerez, el realengo continuó suponiendo la base contributiva de esta zona.

\section{Territorios de señorío del subpartido de Jerez}

A lo largo de los años centrales del siglo XV los territorios de señorío del subpartido de Jerez aumentaron de forma significativa. Los más importantes concejos de esta región, salvo la propia cabeza del subpartido y Carmona, acabaron en manos de la nobleza, especialmente en las de las familias de los Guzmán y los Ponce de León, que dieron el principal impulso al gran avance señorializador que vivieron estas tierras en esta etapa ${ }^{69}$. De esta forma, los Guzmanes, señores ya de Sanlúcar de Barrameda ${ }^{70}$ y del condado de Niebla, se hicieron en 1440 con Medina Sidonia, tras canjearla por la plaza de la Algaba. Cinco años después, en virtud a su apoyo a Juan II durante la guerra con los infantes de Aragón, el conde don Juan de Guzmán, cabeza visible de la familia recibiría, además, el ansiado título ducal $^{71}$. Y sus estados no dejarían de aumentar. En 1462 la lista de sus dominios en este subpartido es, cuanto menos, impresionante ${ }^{72}$ : entre las unidades fiscales que contribuían al pedido poseían ya las villas de Sanlúcar de Barrameda, Trebujena, Alventos y Copero ${ }^{73}$. De entre todas ellas, no podemos dejar de hacer una especial mención a Sanlúcar. Ésta era, sin duda alguna, una de las posesiones más apreciadas por la casa ducal. Importante plaza comercial, que actuaba como antepuerto de la ciudad de Sevilla, proporcionaba cuantiosos y sólidos ingresos a los Medina Sidonia a través de rentas como su almojarifazgo ${ }^{74}$.

Los Ponce de León, por su parte, aunque no llegaron a alcanzar la preponderancia de los Guzmanes en este territorio, vieron ampliarse sus dominios con la

66. M.A. LADERO QUESADA. "Los señoríos medievales en el ámbito de Cádiz y Jerez de la Frontera", En la España Medieval, nº 2 (1982), p. 546.

67. M. GONZÁLEZ JIMÉNEZ. “La Baja Andalucía”... p. 11

68. Véase Anexo.

69. M.A. LADERO QUESADA.“Los señoríos medievales en el ámbito de Cádiz...”, pp. 550 y ss.

70. Para un acercamiento a la realidad de esta plaza a fines de la Edad Media véase A. MORENO OLLERO. Sanlúcar de Barrameda a fines de la Edad Media, Diputación Provincial de Cádiz, Cádiz, 1983.

71. M.A. LADERO QUESADA. “Los señoríos medievales en el ámbito de Cádiz...”, p. 551

72. A fines de siglo los Medina Sidonia tenían bajo su control a poco más del $25 \%$ de la población del todo el sector gaditano. M. GONZÁLEZ JIMÉNEZ. "La Baja Andalucía...”, p. 15.

73. AGS, EMR, Leg. 10, ff. 100r-101r.

74. M. GONZÁLEZ JIMÉNEZ. "La Baja Andalucía...”, p. 31. 
adquisición de Arcos de la Frontera, junto con el título condal. Ésta había sido una de las escasas plazas de realengo hasta ese momento del subpartido de Jerez. A ella se unieron otras adquisiciones de menor relevancia (los Palacios, Santa María de Guadajoz y, durante un período de tiempo, la propia ciudad de Cádiz), pero que, unidos a los que ya poseían en otras regiones del Arzobispado de Sevilla y el Obispado de Cádiz, convirtieron a los señores de Arcos en uno de los linajes que más territorios concentraba en sus manos en toda la Baja Andalucía ${ }^{75}$.

Finalmente, y pese a la importancia perdida con el paso del tiempo en esta zona, el linaje de la Cerda también debe ser tenido en cuenta. Entre las poblaciones que contribuían al pedido bajo su dominio sobresale el Puerto de Santa María ${ }^{76}$, rica localidad marinera de la que extraerán pingües beneficios.

En definitiva, vemos como aquellos territorios más importantes y con una mayor proyección económica, quedaron vinculados en esta fase a grandes linajes, que sustentaron el poderío de sus casas en buena medida sobre los beneficios que obtenían de los mismos. En algunos casos, incluso, vemos como junto al dominio de estos concejos alcanzaron importantes beneficios fiscales, como es el caso de Arcos, que no contribuyó nunca en el pago del pedido ${ }^{77}$.

\section{El predominio del Señorío. El subpartido de Niebla}

La imagen que el subpartido de Niebla ${ }^{78}$ presentaba en el siglo XV era un claro contrapunto a la del subpartido hispalense. Aquí, la importancia del señorío era tal que había fagocitado prácticamente a todas las propiedades de la Corona. En la zona onubense únicamente se mantuvieron dentro del realengo aquellos territorios que la ciudad de Sevilla dominaba en la zona de la Sierra ${ }^{79}$, de los que ya hablamos anteriormente. Este subpartido mostró, pues, una evolución bastante alejada de la que Alfonso X había planificado para ella tras su conquista ${ }^{80}$. La idea inicial del rey sabio había sido la de crear un poderoso territorio bajo dominio real que contara con Niebla como cabeza visible, pero la situación sufriría una clara involución con el paso del tiempo ${ }^{81}$. El inicio de la gran transformación se produciría con el ascenso al trono de Enrique II, que había tratado de apuntalar su posición mediante la concesión de numerosas mercedes al estamento nobiliario, abriendo

75. M.A. LADERO QUESADA. “Los señoríos medievales en el ámbito de Cádiz...”, p. 551.

76. Sobre esta localidad puede consultarse la obra de J.J. IGLESIAS RODRÍGUEZ, El Puerto de Santa María, Diputación Provincial de Cádiz, Cádiz, 1985.

77. Véase Anexo.

78. Para el desarrollo y evolución de este territorio puede consultarse M.A. LADERO QUESADA. Niebla, de reino a condado. Noticias del Algarbe andaluz en la Baja Edad Media, Real Academia de Historia, Madrid, 1992; y A.M. ANASAGASTI VALDERRAMA y L. RODRÍGUEZ LIÁÑEZ. Niebla y su tierra en la Baja Edad Media: historia y documentos. Diputación de Huelva, Huelva, 2006.

79. Y sólo lo hicieron de forma temporal, ya que, como hemos señalado, acabaron en manos del Arzobispo de Sevilla, M. GONZÁLEZ JIMÉNEZ. "La Baja Andalucía...”, p. 11.

80. M.A. LADERO QUESADA. "Los señoríos medievales onubenses...”, p. 206.

81. M.A. LADERO QUESADA. "Los señoríos medievales onubenses...", pp. 207 y ss. 
de esta manera una vía que la nobleza andaluza no dudó en aprovechar para establecer las bases de unos extensos dominios, que no harían sino acrecentarse con el paso del tiempo.

De esta manera, tras una serie de vicisitudes, el señorío de Niebla, con el título condal y todos los núcleos de población insertos en su territorio, pasó a manos de los Guzmán. Desde esta base privilegiada fueron aumentando los estados de esta familia, sobre todo a través de compras y una acertada política matrimonial. Es así como se hicieron con Huelva, parte de la dote que los de la Cerda otorgaron a don Juan de Guzmán en 1434 por su matrimonio con doña María, miembro de esta familia ${ }^{82}$. Hasta entonces la ciudad onubense, aunque de cierta relevancia, no había presentado indicios de la importancia que podía llegar a adquirir. Sería, precisamente, bajo dominio de los señores de Niebla cuando este concejo diera muestras de una incipiente prosperidad, que aumentará gracias al desarrollo del comercio y de la navegación marítima en esta zona ${ }^{83}$.

Junto a Huelva, Almonte y Bollullos completaron las unidades fiscales del pedido pertenecientes a los extensos dominios de los Guzmanes en este subpartido. Para mostrar la importancia que esta familia llegó a tener sobre la zona baste señalar que a finales de la centuria cerca de la mitad de la población del área onubense se encontraba bajo su autoridad ${ }^{84}$.

Al igual que ocurrió con el territorio jerezano, las tierras de Niebla atrajeron la atención de otros grandes linajes además de los Guzmanes. Así, los de la Cerda, futuros señores de Medinaceli, emparentados y en buenas relaciones con los señores de Niebla, dominaban el poderoso señorío de Gibraleón, así como el más modesto de La Palma ${ }^{85}$, mientras que los Stuñigas mantenían plazas como las de Lepe y la de Villalba ${ }^{86}$. Junto a estas importantes casas cabe destacar también el linaje de los Portocarreros que, estrechamente vinculados al Concejo de la ciudad de Sevilla, serán los dueños de una de las poblaciones más importantes de esta zona: Moguer ${ }^{87}$.

Junto a este predominio señorial el otro aspecto que caracteriza a este territorio es su particular carga contributiva. A diferencia de lo ocurrido en las otras zonas ya estudiadas, aquí la cabeza del subpartido compartió su importancia con las villas que eran sus antepuertos, como es el caso de Moguer, Huelva y Gibraleón ${ }^{88}$. El

82. M.A. GARCÍA-ARRECIADO BANATERO. "La villa de Huelva en la Baja Edad Media", Huelva en su Historia, vol. 2, 1988, p. 181.

83. M.A. GARCÍA-ARRECIADO BANATERO. "La villa de Huelva..." p. 215.

84. M. GONZÁLEZ JIMÉNEZ. "La Baja Andalucía...”, p. 15.

85. AGS, EMR, Leg. 10, ff. 100r-101r.

86. Contamos con un detallado análisis de la evolución del dominio señorial en el territorio de Huelva en M.A. LADERO QUESADA. "Los señoríos medievales onubenses. Período de formación", en J. DE LA MATA CARRIAZO RUBIO y J.M. MIURA ANDRADES. (coord.) Huelva en la Edad Media: reflexiones, aportaciones y nuevas perspectivas veinte años después, Universidad de Huelva, Huelva, 1998, pp. 203-228.

87. Un estudio detallado sobre esta plaza bajo el dominio de la familia Portocarrero lo encontramos en A. GONZÁLEZ GÓMEZ. Moguer en la Baja Edad Media, Instituto de Estudios Onubenses, Huelva, 1977, pp. 55-70.

88. M.A. LADERO QUESADA, “Los señoríos medievales en el ámbito de Cádiz...”, p. 544. 
predominio contributivo de Niebla sobre el territorio fiscal del que actuaba como cabeza era el más tenue de todo el Arzobispado de Sevilla y el Obispado de Cádiz. Esta situación se refleja claramente en el porcentaje del pago de este condado (éste actuaba como una unidad fiscal ${ }^{89}$ ) con respecto a la totalidad del subpartido, no alcanzando nunca el $25 \%$ del mismo, algo que la dejaba muy lejos del claro dominio que las otras cabezas de subpartido del Arzobispado ejercían en sus territorios. Parece que Niebla no contó con un poderío económico y demográfico que le permitiera cargar con la mayor parte del peso del pedido de la manera que lo hacían Sevilla, Écija o Jerez. Todo parece indicar que fue el desarrollo del proceso señorializador que vivieron estas tierras a lo largo del siglo XIV la que llevó a esta situación, al reducir las tierras sobre los que esta plaza ejercía su jurisdicción y acabar, de esta forma, con una de las principales bases de la prosperidad de esta unidad fiscal ${ }^{90}$.

\section{El SUBPARTIDO DE ÉCIJA}

El subpartido menos importante de todo el Arzobispado de Sevilla y el Obispado de Cádiz era el de Écija. Éste englobaba unas pocas poblaciones, cuyo peso en la contribución en conjunto era, además, el menor de todos los territorios que hemos analizado hasta ahora ${ }^{91}$. La mayor parte del la misma se dividía entre los concejos de Écija, cabeza del subpartido, que llegó a suponer más de la mitad de lo que éste aportaba, siguiendo así la estela de Jerez y Sevilla; y Marchena.

En el caso de Écija vemos como su dominio jurisdiccional presenta una curiosa evolución a lo largo del siglo XV. Situada entre dos plazas tan importantes como eran Sevilla y Córdoba, esta localidad pasó de ser tierra de realengo a convertirse en parte del patrimonio del príncipe de Asturias hacia $1442^{92}$, permaneciendo bajo el mismo hasta el ascenso al trono de éste en 1454, cuando volvería a pasar a formar parte de los territorios de la Corona. En la época que aquí estudiamos Écija aún estaba lejos de tener la importancia ${ }^{93}$ que alcanzaría un siglo después, cuando se convirtiera en uno de los concejos con más peso económico de la Baja Andalucía, pero ya era lo suficientemente rico como para sostener una carga fiscal importante como la que ya pagaba en el pedido $o^{94}$. Tras pasar a manos del príncipe Enrique parece que éste, siguiendo la habitual tendencia de muchos nobles en sus estados, no dudó en secuestrar rentas reales en su beneficio. Estas sumas,

89. Véase tabla 2 del Anexo.

90. A. COLLANTES DE TERÁN SÁNCHEZ. "Las ciudades andaluzas...”, pp. 48-49.

91. La contribución del subpartido de Écija solía suponer en torno al 10\% del total del Arzobispado de Sevilla y el Obispado de Cádiz. Véase Anexo.

92. M. GONZÁLEZ JIMÉNEZ. "Écija, señorío de los príncipes de Asturias (siglo XV)", en Écija en la Edad Media y el Renacimiento, Universidad de Sevilla, 1993, pp. 53-66.

93. J.M. NAVARRO DOMÍNGUEZ. "Expansión económica en la Baja Andalucía en el siglo XVI. El modelo de la ciudad de Écija”, en Écija en la Edad Media y el Renacimiento, Universidad de Sevilla, 1993, p. 216.

94. Véase Anexo. 
fundamentalmente derivadas del pedido, las monedas y las alcabalas, supusieron grandes beneficios para el heredero al trono ${ }^{95}$, resultando significativos incluso dentro de los ya abundantes recursos que aportaban a su Hacienda sus dominios dispersos por toda la Corona.

El resto de concejos del subpartido pertenecían a la nobleza o a las órdenes militares. Así ocurrió con Marchena, el segundo núcleo que más contribuía en este territorio. Ésta fue la perla de los estados de los Ponce de León durante el siglo XIV y buena parte del XV. De hecho, los miembros de esta familia fueron conocidos como señores de la villa hasta que recibieron el dominio y el título de condes de Arcos en 1440. Pese a todo, la misma continuó siendo uno de sus dominios favoritos y lugar de residencia a lo largo de lo que quedaba de siglo ${ }^{96}$. Un dominio que, junto al de Mairena, llevó a que los Ponce de León fueran el linaje más importante en todo este territorio. Junto a ellos, también merece la pena señalar el elevado número de localidades que la Orden de San Juan mantuvo bajo su autoridad (Tocina, Alcolea, Lora y Setefilla).

\section{TERRITORIOS EXENTOS}

Tras presentar una imagen general de los diversos subpartidos que contribuyen en el pago del pedido, no podemos dejar de hacer una mención, aunque sea de forma breve, a aquellos territorios que contaron con exención en la contribución del mismo.

Este beneficio fiscal con la que contaron algunas poblaciones podía proceder de una concesión del monarca o de la cabeza del subpartido a la que pertenecieran. Las primeras solían ser el producto de diversos intentos por parte de la monarquía para favorecer la repoblación de esta zona y solían tener un carácter permanente. Así lo podemos observar en el alfoz de la ciudad hispalense, donde conocemos diversos casos, como el de Real o Realejo, que contaba con un privilegio concedido por Alfonso X en 1280, posteriormente confirmado por el Concejo de Sevilla en $1408^{97}$. También fue bastante frecuente el otorgamiento de importantes exenciones por parte del monarca a concejos de señorío, como forma de asegurar el apoyo de los titulares de los mismos o recompensarlos. De esta forma, podremos entender la desaparición de Palos de las relaciones de recaudación del pedido o la franqueza que recibió Cádiz por parte de los Reyes Católicos en 1478, como consecuencia de los "buenos y leales servicios" que el señor de esta plaza, don Rodrigo Ponce de León, conde de Arcos, les había prestado ${ }^{98}$.

95. Un reflejo de los mismos para el período 1443-1454 lo encontramos en "Écija, señorío..." pp. 58-59.

96. A. FRANCO SILVA. "La villa de Marchena en la Baja Edad Media. Linaje, rentas, posesiones y ordenanzas", Actas de las II Jornadas de Historia de Marchena, Marchena, 1997, pp. 309-344.

97. F.J. ROMERO ROMERO. Sevilla y los pedidos de Cortes...p. 20.

98. Colección de privilegios, franquezas, exenciones y fueros concedidos a varios pueblos y corporaciones de la corona de Castilla, copiados de orden de S. M. de los registros del Real Archivo de Simancas, Imprenta Real, Madrid, 1830, pp. 414 y ss. 
Las exenciones derivadas de una decisión del Concejo que actuaba como cabeza de subpartido, por su parte, eran frecuentemente de carácter temporal y estaban destinadas a afrontar una coyuntura demográfica o económica negativa. Entre las concedidas por la ciudad de Sevilla podemos destacar los casos de El Bodonal y La Marotera, que alcanzaron esta situación en 1442 ante la negativa situación que atravesaban en esos momentos ${ }^{99}$, aplicándoseles una condición de beneficio similar a la que ya disfrutaban Las Cabezas de San Juan, San Nicolás del Puerto o El Cerro por motivos similares ${ }^{100}$. Así mismo, contamos con el ejemplo de Guillena, que recibió la exención del pago del pedido durante diez años en $1448^{101}$ o con el de Burguillos, bien documentado gracias al pleito que este concejo mantuvo con los arrendadores de la moneda de los años de 1451 y 1452, por la intención de estos agentes fiscales de cobrar este subsidio en dicha plaza, pese a que su franqueza se hacía extensiva también a este ingreso ${ }^{102}$.

Unas condiciones particularmente difíciles para el proceso de repoblación se dieron en la zona fronteriza con Granada, donde los frecuentes golpes de mano por parte de fuerzas del emirato nazarí dificultaban este proceso. Las acuciantes necesidades defensivas de la región hacían necesario atraer población hacia este territorio, por lo que era necesario ofrecer condiciones que atrajesen nuevos pobladores. La amplia experiencia acumulada por la monarquía en este sentido indicaba que uno de los recursos más efectivos era el de la concesión de amplias exenciones sobre los pechos de la Corona. De esta forma, los concejos que quedaron insertos dentro de la amplia región conocida como "banda morisca" fueron eximidos de la contribución a este subsidio así como de otros impuestos reales, entre otras ventajas y privilegios ${ }^{103}$.

Muchos de estos territorios fronterizos lograron mantener este tipo de ventajas fiscales, aún cuando la frontera experimentó un proceso de avance que la alejaba de los mismos. Así lo podemos observar en la amplia franja costera comprendida entre Cádiz y Gibraltar ${ }^{104}$. La importancia estratégica de las plazas situadas en esta región determinó que recibieran importantes privilegios desde su conquista, aspecto que se afianzó durante la época de la denominada batalla del Estrecho. La importancia defensiva de las mismas frente a un eventual ataque norteafricano y

99. F.J. ROMERO ROMERO. Sevilla y los pedidos de Cortes...p. 22.

100. F.J. ROMERO ROMERO. Sevilla y los pedidos de Cortes...p.20.

101. Esta situación queda reflejada en los repartimientos del pedido de 1452. AMS, P. May., Rollo 265, Caja 52, Pedido 1452.

102. "[...] que porque el dicho lugar se poblase mejor de lo que estaba, la dicha ciudad les hubiere dado cierta franqueza por cierto tiempo, que no pagasen los vecinos y moradores que en el dicho lugar viviesen y morasen pedidos ni monedas ni otros pechos [...] no embargante lo contenido en la dicha carta de la dicha merced, que por parte de los arrendadores que habían sido de las monedas pasadas de que el rey se quisiera servir de esta ciudad y su tierra los años que pasaron de 1451 y 1452 , habían sido y eran fatigados demandándoles las dichas monedas."AMS, Pap. May., Rollo 266, Caja 55, Pedido 1454.

103. I. MONTES ROMERO-CAMACHO. "Sevilla y la frontera de Granada durante el reinado de Enrique IV (1454-1474)", en C. SEGURA GRAIÑO. Relaciones exteriores del Reino de Granada, Coloquio de Historia Medieval andaluza, Instituto de Estudios Almerienses, Almería, 1988, p. 127.

104. Esta última plaza no sería conquistada hasta 1462. 
la capacidad señorial para defender las prerrogativas de los territorios que se encontraban bajo su dominio, favoreció que esta situación se mantuviese a lo largo de todo el siglo XV. De esta forma, una buena parte del Arzobispado de Sevilla y el Obispado de Cádiz quedó fuera de la organización territorial del pago del pedido $^{105}$.

\section{CONCLusiones}

Tal y como hemos podido observar a lo largo del presente artículo si algo caracterizó la imagen del espacio fiscal de la recaudación del pedido en el Arzobispado de Sevilla y el Obispado de Cádiz, esto fue su estabilidad. Si atendemos a los datos que poseemos ${ }^{106}$ podemos ver como el único cambio visible en la misma, si no tenemos en cuenta el caso excepcional de 1443, fue la desaparición de Palos en las relaciones de pueblos que pagaban este subsidio y el hecho de que Dos Hermanas pasase a contribuir junto a Sevilla. Además de estas ligeras modificaciones no conocemos ningún cambio más hasta la sustitución de los servicios de Cortes por el sistema de recaudación de la Hermandad en 1478. Estamos, por tanto, ante una organización territorial prácticamente inalterable, aspecto que, si bien parece ser frecuente entre los partidos de la mitad sur del territorio castellano, contrasta con las frecuentes transformaciones que experimentaron aquellos situados al norte del Tajo.

Pero antes de llegar al resultado aquí expuesto debió de tener lugar un proceso de conformación, tal y como parecen reflejar los primeros repartimientos de los que tenemos noticias. No obstante, no contamos con información suficiente sobre este aspecto clave para entender como se conformó y consolidó el Arzobispado de Sevilla y el Obispado de Cádiz como partido del pedido regio, algo que esperamos poder subsanar en un futuro cercano. Lo único que parece evidente es que la configuración de este espacio fiscal fue el producto lógico de las necesidades de la contribución del subsidio que aquí estudiamos ${ }^{107}$. Un modelo organizativo basado en una clara jerarquización de los espacios jurisdiccionales existentes, como el que finalmente fue adoptado, parecía, sin lugar a dudas, lo más adecuado para el correcto funcionamiento de un subsidio en el que eran las autoridades fiscales de cada uno de dichos espacios los que ponían en funcionamiento el proceso de recaudación.

Si bien este hecho llevó a que en un primer momento la organización fiscal respondiera a la realidad de este territorio, el carácter estático de la geografía físcal del pedido acabó determinando que no se produjese ninguna adaptación de ésta a las transformaciones que fueron teniendo lugar en esta zona con el paso del tiempo. En este sentido, hemos mostrado como este partido se vio afectado por

105. Así se puede observar en el mapa que presentamos en el Anexo.

106. Véase Anexo.

107. Situación que comparte con el resto de espacios fiscales de la Corona. En torno a este aspecto D. ALONSO GARCÍA. “Crear espacios...”, pp. 47 y ss. 
un proceso de señorialización muy intenso, algo que influyó de manera notable en la recaudación efectiva del pedido. Un proceso que llevó a que la división de este partido en los cuatro subpartidos analizados tuviera cada vez menos sentido. La distinción entre tierras de señorío y realengo resultaba mucho más práctica y funcional a los recaudadores mayores, los agentes fiscales que eran los máximos responsables de la recaudación del pedido, a la hora de llevar a cabo sus funciones. No tenia sentido seguir teniendo en consideración una división en subpartidos que había quedado obsoleta al no tener en cuenta las transformaciones jurisdiccionales que habían tenido lugar. Así lo muestra el hecho de que aunque, en teoría, el pedido siguiera utilizando la división territorial que aquí hemos presentado, existan algunas relaciones de pago que nos muestren que la distinción entre los diversos dominios señoriales y las tierras de realengo era el criterio realmente utilizado en la práctica por los agentes fiscales a la hora de llevar a efecto la recaudación de esta ayuda ya en la segunda mitad del siglo ${ }^{108}$. Dicho criterio, que constituyen uno de los pilares del análisis del presente artículo, continuó cobrando importancia con el paso del tiempo, hasta ser definitivamente adoptado por los modernos servicios de Cortes ${ }^{109}$.

Otro aspecto de especial relevancia al que hemos prestado atención, y que nos permite comprender la jerarquización del espacio ${ }^{110}$, amén de muchos otros aspectos; son los niveles de contribución de cada una de las unidades fiscales que conformaron este gran partido fiscal. Junto a la ya señalada importancia del Arzobispado de Sevilla y el Obispado de Cádiz en la totalidad de la Corona, al que ya hemos hecho mención, el otro elemento que caracterizó los niveles de pago de este territorio fue el hecho de que los porcentajes de contribución de las diversas unidades fiscales no experimentaron apenas modificaciones a lo largo del siglo. Una fosilización que, al igual que ocurre con el espacio fiscal, nos transmite una imagen fija que no se adapta a los significativos cambios demográficos y económicos que experimentó esta región a lo largo del siglo XV.

De esta manera, y pese a que teóricamente el pedido era repartido teniendo en cuenta el número de pecheros y su capacidad económica en cada unidad fiscal mediante la realización de padrones de cuantía ${ }^{111}$, cada una de los mismas había de hacer frente a un porcentaje que no tuvo en consideración estas circunstancias. Ello permite explicar, en parte, las constantes quejas de los procuradores de Cortes ante el monarca señalando lo desigual que resultaba la recaudación del pedido y la necesidad de que se pusieran al día los niveles de contribución.

108. Este es el caso de la relación con la que contamos para 1469 en EMR, Leg 14, f. 197 r.

109. Así podemos apreciarlo en la relación de los mismos insertos en J.M. CARRETERO ZAMORA. La averiguación... pp. 1425-1495.

110. Sobre este aspecto ya incidió el profesor A. COLLANTES DE TERÁN SÁNCHEZ. "Las ciudades andaluzas...", pp. 45 y ss.

111. Para una visión general sobre los padrones de cuantía F. ROMERO ROMERO, Sevilla y los pedidos de Cortes..., pp. 33-62; A. COLLANTES DE TERÁN. Sevilla en la Baja Edad Media, pp. 20-26; A. COLLANTES DE TERÁN SÁNCHEZ. "Un informe sobre la confección de los padrones de cuantía", Historia, instituciones, documentos, n¹9 (1992), pp. 149-160; y J. RODRÍGUEZ SARRIA. “Cobrar para el rey?...”, pp. 85 y ss. 
Especial daño sufrieron por esta situación los territorios de realengo del Arzobispado de Sevilla y el Obispado de Cádiz, que asumieron la mayor parte de la carga fiscal desde un principio. Una situación que no hizo sino agravarse, ya que algunos de los procesos de desarrollo económico y demográfico más significativos de esta etapa se vivieron, precisamente, en núcleos de señorío. Así, las diferencias de contribución entre ambos tipos de territorio fueron cada vez más acusadas, al no tenerse en cuenta estos hechos. Lo podemos observar claramente en la franja costera atlántica, que si bien ya contaba con gran relevancia a principios de siglo, como muestran sus elevados niveles de contribución, vivió un espectacular desarrollo al amparo del crecimiento de las rutas de comercio internacional que por allí transcurrían sin que ello afectase apenas a sus niveles de pago en el pedido.

Estos territorios de señorío, no hemos de olvidarlo, solían suponer un quebradero de cabeza para los recaudadores de esta ayuda. Como ya señalamos los impuestos regios se veían amenazados en los mismos por las constantes confiscaciones que los señores solían llevar a cabo. A ello hay que unir la capacidad de resistencia de éstos, que solían aprovechar su posición de fuerza para negociar con la Corona el pago de las rentas reales en sus dominios ${ }^{112}$. Así, estos señores podían acabar llegando a una especie de "pacto fiscal", que beneficiaba a los pecheros que moraban en sus estados. Una situación ventajosa que, incluso, llegó a favorecer el trasvase de población de territorios de realengo a los de señorío. Así lo muestran diversas disposiciones adoptadas por el monarca en este sentido, como es el caso de ésta de las Cortes de Burgos de 1430:

[...] E algunos delos vezinos pecheros della van a poblar algunos logares de sennorios donde son mas escusados e rreleuados delos dichos pechos e trabajos, por manera que lo que estos atales auian de pechar, se cargan a los otros pecheros que quedan en las mis çibdades e villas donde ellos parten, e que les rrecreçe tanto danno que si en ello no se rremediase, la mi tierra se despoblaria mas cada dia ${ }^{113}$.

Todo ello acentuó más la brecha fiscal existente entre estos territorios, una situación que no encontró solución durante los años en los que fue recaudado el servicio de Cortes medieval y que, incluso, pervivió con los subsidios de la Hermandad y los primeros años del moderno servicio de Cortes. Habría que esperar a que se emprendiera la célebre averiguación realizada durante el reinado de Carlos $\mathrm{V}^{114}$ para que finalmente se adoptaran medidas efectivas sobre un problema que afectó a los ingresos extraordinarios de la Corona durante todo el siglo XV y parte del XVI.

112. M.A. LADERO QUESADA. "Los señoríos medievales..." pp. 563-564.

113. Cortes de los antiguos reinos de León y de Castilla, Tomo tercero, Real Academia de la Historia, Madrid, 1866, p. 94.

114. Sobre este proceso consúltese la magnífica obra del profesor Carretero a la que hemos hecho diversas alusiones a lo largo del presente artículo. J.M. CARRETERO ZAMORA. La averiguación... 


\section{Anexo}

1-. Relación de grandes partidos en el pago del pedido de 1462 en la Corona de Castilla ${ }^{115}$.

\begin{tabular}{|c|c|c|}
\hline Partidos & Mrs & Porcentaje \\
\hline $\begin{array}{l}\text { Arzobispado de Sevilla con el Obispado de } \\
\text { Cádiz }\end{array}$ & 1.961 .364 & 6,41 \\
\hline Obispado de Cuenca & 1.766 .457 & 5,77 \\
\hline $\begin{array}{c}\text { Arzobispado de Santiago con el Obispado } \\
\text { de Tuy }\end{array}$ & 1.690 .888 & 5,52 \\
\hline Obispado de Ávila & 1.447 .675 & 4,73 \\
\hline Obispado de Segovia & 1.367 .947 & 4,47 \\
\hline Obispado de Orense & 1.148 .658 & 3,75 \\
\hline Obispado de León & 1.095 .997 & 3,58 \\
\hline Obispado de Osma & 949.747 & 3,10 \\
\hline Arcedianato de Toledo & 901.112 & 2,94 \\
\hline Obispado de Sigüenza & 886.624 & 2,89 \\
\hline Arcedianato de Guadalajara & 855.411 & 2,79 \\
\hline Las cuatro sacadas de Asturias de Oviedo & 828.706 & 2,70 \\
\hline Obispado de Astorga & 807.673 & 2,64 \\
\hline Obispado de Córdoba & 763.396 & 2,49 \\
\hline Obispado de Salamanca & 710.330 & 2,32 \\
\hline Merindad de Campos con Palencia & 677.856 & 2,21 \\
\hline Obispado de Jaén & 660.203 & 2,15 \\
\hline Merindad de Castrojeriz & 631.919 & 2,06 \\
\hline Merindad de Castilla la Vieja & 597.449 & 1,95 \\
\hline Obispado de Lugo & 595.274 & 1,94 \\
\hline Obispado de Mondoñedo & 590.868 & 1,93 \\
\hline Obispado de Plasencia & 572.285 & 1,87 \\
\hline Obispado de Badajoz & 498.223 & 1,62 \\
\hline Merindad de Santo Domingo de Silos & 488.104 & 1,59 \\
\hline Arcedianato de Madrid & 472.686 & 1,54 \\
\hline Merindad de Carrión & 466.544 & 1,52 \\
\hline Infantazgo de Valladolid & 450.148 & 1,47 \\
\hline Tierra de Guipúzcoa & 435.985 & 1,42 \\
\hline Sacada de Zamora & 427.115 & 1,39 \\
\hline Arcedianato de Calatrava & 405.586 & 1,32 \\
\hline Obispado de Cartagena & 397.424 & 1,29 \\
\hline Merindad de Rioja & 388.170 & 1,26 \\
\hline Merindad de Asturias de Santillana & 367.732 & 1,20 \\
\hline Merindad de Monzón & 352.443 & 1,15 \\
\hline Merindad de Cerrato & 342.503 & 1,11 \\
\hline
\end{tabular}

115. AGS, EMR, Leg. 17, ff. 4r-5r. 


\begin{tabular}{|c|r|r|}
\hline Obispado y sacada de Coria y Cáceres & 341.246 & 1,11 \\
\hline Merindad de Logroño & 302.993 & 0,99 \\
\hline Merindad de Aguilar de Campoo & 295.044 & 0,96 \\
\hline Arcedianato de Talavera & 289.892 & 0,94 \\
\hline Merindad de Allendebro & 282.203 & 0,92 \\
\hline Arcedianato de Alcaraz & 274.296 & 0,89 \\
\hline Merindad de Saldaña & 270.773 & 0,88 \\
\hline Merindad de Candemuño & 260.975 & 0,85 \\
\hline Sacada de Toro & 250.135 & 0,81 \\
\hline Merindad de Bureba & 223.556 & 0,73 \\
\hline Merindad de Villadiego & 222.829 & 0,72 \\
\hline Merindad de Burgos & 200.492 & 0,65 \\
\hline Obispado de Ciudad Rodrigo & 155.595 & 0,50 \\
\hline Merindad de Liébana & 134.189 & 0,43 \\
\hline Merindad de Pernia & 84.315 & 0,27 \\
\hline TOTAL & $\mathbf{3 0 . 5 8 9 . 0 3 5}$ & $\mathbf{1 0 0}$ \\
\hline
\end{tabular}




\begin{tabular}{|c|c|c|c|c|c|c|c|c|c|c|c|}
\hline \multirow[b]{2}{*}{ Subpartido fiscal } & \multirow[b]{2}{*}{ Unidad fiscal } & \multirow[b]{2}{*}{ Condición } & \multicolumn{3}{|c|}{ Pedido $1411^{116}$} & \multicolumn{3}{|c|}{ Pedido $1455^{117}$} & \multicolumn{3}{|c|}{ Pedido $1477^{118}$} \\
\hline & & & Mrs. & $\begin{array}{c}\% \\
\text { Partido }\end{array}$ & $\%$ Total & Mrs. & $\begin{array}{c}\% \\
\text { Partido }\end{array}$ & \% Total & Mrs. & $\begin{array}{c}\% \\
\text { Partido }\end{array}$ & \% Total \\
\hline Sevilla & $\begin{array}{c}\text { Sevilla y su } \\
\text { tierra (Dos } \\
\text { Hermanas) }^{119}\end{array}$ & Realengo & $1.009 .417,00$ & 87,85 & 51,24 & $898.510,00$ & 87,99 & 51,54 & $1.198 .013,00$ & 88,16 & 51,86 \\
\hline Sevilla & Dos Hermanas & Realengo & $1.454,00$ & 0,13 & 0,07 & - & - & - & - & - & - \\
\hline Sevilla & Cantillana & Señorío & $15.530,00$ & 1,35 & 0,79 & $13.800,00$ & 1,35 & 0,79 & $18.004,00$ & 1,32 & 0,78 \\
\hline Sevilla & Villaverde $^{120}$ & Señorío & 2588,00 & 0,23 & 0,13 & $2.290,00$ & 0,22 & 0,13 & $3.053,00$ & 0,22 & 0,13 \\
\hline Sevilla & Brenes & Señorío & $3.621,00$ & 0,32 & 0,18 & $3.210,00$ & 0,31 & 0,18 & $4.281,00$ & 0,32 & 0,19 \\
\hline Sevilla & $\begin{array}{c}\text { Umbrete con } \\
\text { Aguazul e } \\
\text { Aguazulejo }^{121} \\
\end{array}$ & Señorío & $1.300,00$ & 0,11 & 0,07 & $4.200,00$ & 0,41 & 0,24 & $6.600,00$ & 0,49 & 0,29 \\
\hline Sevilla & Rianzuela $^{122}$ & Señorío & 650,00 & 0,06 & 0,03 & 570,00 & 0,06 & 0,03 & 760,00 & 0,06 & 0,03 \\
\hline Sevilla & Zalamea $^{123}$ & Señorío & $6.209,00$ & 0,54 & 0,32 & $5.500,00$ & 0,54 & 0,32 & $4.026,50$ & 0,3 & 0,17 \\
\hline Sevilla & Almonaster ${ }^{124}$ & Señorío & $4.067,00$ & 0,35 & 0,21 & $3.610,00$ & 0,35 & 0,21 & $4.802,50$ & 0,35 & 0,21 \\
\hline
\end{tabular}

116. AMS, Pap. May., Rollo 205, Pedido de 1411.

117. AGS, EMR, Leg 1, fols 596r-600r.

118. Junto al pedido de este año se cobro otro, denominado "de la plata de las Iglesias" destinado a devolver los préstamos realizados por las iglesias y monasterios de la Corona a la monarquía en los años anteriores y que aquí no tenemos en cuenta. Las cifras del pedido de este año, que aquí presentamos han sido tomadas de R. CARANDE Y THOVAR, y J. DE LA MATA CARRIAZO, El tumbo de los Reves Católicos en el Concejo de Sevilla tomo II (años 1477-1479), Universidad de Sevilla, Sevilla, 1968, pp. 9-14.

119. De los años que conservamos datos para el pedido en el Arzobispado de Sevilla y el obispado de Cádiz, el único en el que Dos Hermanas actúa como receptoría independiente es en 1411. En los demás paga junto con Sevilla su contribución en este subsidio.

120. Actual Villaverde del Río (provincia de Sevilla).

121. Umbrete (provincia de Sevilla). Las entidades dependientes de Aguazul y Aguazulejo son hoy despoblados pertenecientes a este municipio.

122. Despoblado localizado en el término municipal de Bollullos de la Mitación (provincia de Sevilla).

123. Zalamea la Serena (provincia de Badajoz).

124. Almonaster la Real (provincia de Huelva). 


\begin{tabular}{|c|c|c|c|c|c|c|c|c|c|c|c|c|}
\hline 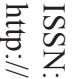 & Sevilla & $\begin{array}{c}\text { Gandul y } \\
\text { Marchenilla }^{125}\end{array}$ & Señorío & $4.717,00$ & 0,41 & 0,24 & $4.190,00$ & 0,41 & 0,24 & $5.587,00$ & 0,41 & 0,24 \\
\hline 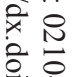 & Sevilla & $\begin{array}{c}\text { Castilleja de la } \\
\text { Cuesta } \\
\end{array}$ & Señorío & 943,00 & 0,08 & 0,05 & 840,00 & 0,08 & 0,05 & $1.120,00$ & 0,08 & 0,05 \\
\hline${ }_{0}^{0}$ & Sevilla & $\begin{array}{c}\text { Castilleja del } \\
\text { Maestre de } \\
\text { Alcántara }^{126}\end{array}$ & Señorío & 382,00 & 0,03 & 0,02 & 340,00 & 0,03 & 0,02 & 453,00 & 0,03 & 0,02 \\
\hline$\vec{N} \ddot{S}$ & Sevilla & Chucena $^{127}$ & Señorío & $1.045,00$ & 0,09 & 0,05 & $3.080,00$ & 0,3 & 0,18 & $4.102,00$ & 0,3 & 0,18 \\
\hline & Sevilla & Caracena & Señorío & 153,00 & 0,01 & 0,01 & 130,00 & 0,01 & 0,01 & 173,00 & 0,01 & 0,01 \\
\hline & Sevilla & Torralba $^{128}$ & Señorío & 459,00 & 0,04 & 0,02 & 400,00 & 0,04 & 0,02 & 533,00 & 0,04 & 0,02 \\
\hline N & Sevilla & Purchena $^{129}$ & Señorío & 790,00 & 0,07 & 0,04 & 700,00 & 0,07 & 0,04 & 933,00 & 0,07 & 0,04 \\
\hline$\omega$ & Sevilla & Mures $^{130}$ & Señorío & $8.542,00$ & 0,74 & 0,43 & $7.590,00$ & 0,74 & 0,44 & $10.120,00$ & 0,74 & 0,44 \\
\hline . & Sevilla & Gatos $^{131}$ & Señorío & $4.717,00$ & 0,41 & 0,24 & $4.190,00$ & 0,41 & 0,24 & $5.586,50$ & 0,41 & 0,24 \\
\hline$=$ & Sevilla & $\begin{array}{c}\text { Villanueva de } \\
\text { Ariscal }^{132}\end{array}$ & Señorío & $13.132,00$ & 1,14 & 0,67 & $8.620,00$ & 0,84 & 0,49 & $11.493,50$ & 0,85 & 0,5 \\
\hline & Sevilla & Estercolinas $^{133}$ & Señorío & $7.650,00$ & 0,67 & 0,39 & $6.800,00$ & 0,67 & 0,39 & $9.066,50$ & 0,67 & 0,39 \\
\hline & Sevilla & Tomares & Señorío & 663,00 & 0,06 & 0,03 & 580,00 & 0,06 & 0,03 & 773,00 & 0,06 & 0,03 \\
\hline & Sevilla & Gelves & Señorío & $6.553,00$ & 0,57 & 0,33 & $7.000,00$ & 0,57 & 0,33 & $7.760,00$ & 0,57 & 0,34 \\
\hline & Sevilla & $\begin{array}{c}\text { Castilleja de } \\
\text { Talhara }^{134}\end{array}$ & Señorío & $7.880,00$ & 0,69 & 0,4 & $5.820,00$ & 0,68 & 0,4 & $9.333,00$ & 0,69 & 0,4 \\
\hline
\end{tabular}

125. Gandul y Marchenilla son actualmente despoblados situados en el término municipal de Alcalá de Guadaira (provincia de Sevilla).

126. Actual Castilleja de Guzmán (provincia de Sevilla).

127. Chucena (provincia de Huelva).

128. Despoblado del término municipal de Chucena (provincia de Huelva).

129. Despoblado del término municipal de Chucena (provincia de Huelva).

130. Actual Villamanrique de la Condesa (provincia de Sevilla).

131. Despoblado del término municipal de Villamanrique de la Condesa (provincia de Sevilla).

132. Villanueva del Ariscal (provincia de Sevilla).

133. Actual Olivares (provincia de Sevilla).

134. Despoblado en el municipio de Benacazón (provincia de Sevilla). 


\begin{tabular}{|c|c|c|c|c|c|c|c|c|c|c|c|}
\hline Sevilla & Algaba y Alarase & Señorío & $21.012,00$ & 1,83 & 1,07 & $18.670,00$ & 1,83 & 1,07 & $24.893,00$ & 1,83 & 1,08 \\
\hline Sevilla & Santiponce & Señorío & $2.448,00$ & 0,21 & 0,12 & $2.170,00$ & 0,21 & 0,12 & $2.893,50$ & 0,21 & 0,13 \\
\hline Sevilla & Gines & Señorío & $3.514,00$ & 0,31 & 0,18 & $3.120,00$ & 0,31 & 0,18 & $4.160,00$ & 0,31 & 0,18 \\
\hline Sevilla & $\begin{array}{c}\text { Carrión de los } \\
\text { Ajos }^{135}\end{array}$ & Señorío & $4.182,00$ & 0,36 & 0,21 & $1.550,00$ & 0,15 & 0,09 & $2.066,50$ & 0,15 & 0,09 \\
\hline Sevilla & Albaida $^{136}$ & Señorío & $12.253,00$ & 1,07 & 0,62 & $10.890,00$ & 1,07 & 0,62 & $14.520,00$ & 1,07 & 0,63 \\
\hline Sevilla & Robaina $^{137}$ & Señorío & $3.149,00$ & 0,27 & 0,16 & $2.800,00$ & 0,27 & 0,16 & $3.733,00$ & 0,27 & 0,16 \\
\hline $\begin{array}{c}\text { TOTAL } \\
\text { REALENGO } \\
\text { SEVILLA } \\
\end{array}$ & & & $1.010 .871,00$ & 87,98 & 51,31 & $898.510,00$ & 87,99 & 51,54 & $1.198 .013,00$ & 88,16 & 51,86 \\
\hline $\begin{array}{c}\text { TOTAL } \\
\text { SEÑORÍO } \\
\text { SEVILLA } \\
\end{array}$ & & & $138.149,00$ & 12,02 & 7,01 & $122.660,00$ & 11,99 & 7,02 & $160.826,5$ & 11,83 & 6,97 \\
\hline $\begin{array}{l}\text { TOTAL } \\
\text { SEVILLA }\end{array}$ & & & $1.149 .020,00$ & 100 & 58,32 & $1.021 .170,00$ & 100 & 58,56 & $1.358 .839,50$ & 100 & 58,83 \\
\hline Jerez & $\begin{array}{l}\text { Jerez de la } \\
\text { Frontera con } \\
\text { Dueñas }\end{array}$ & Realengo & $169.920,00$ & 46,2 & 8,63 & $151.040,00$ & 46,16 & 8,66 & $201.386,50$ & 46,15 & 8,72 \\
\hline Jerez & $\begin{array}{l}\text { Sanlúcar de } \\
\text { Barrameda }\end{array}$ & Señorío & $49.916,00$ & 13,57 & 2,53 & $44.370,00$ & 13,56 & 2,54 & $59.160,00$ & 13,56 & 2,56 \\
\hline Jerez & $\begin{array}{c}\text { Puerto de Santa } \\
\text { María }\end{array}$ & Señorío & $28.241,00$ & 7,68 & 1,43 & $25.100,00$ & 7,67 & 1,44 & $33.466,50$ & 7,67 & 1,45 \\
\hline Jerez & Rota & Señorío & $14.229,00$ & 3,87 & 0,72 & $12.630,00$ & 3,86 & 0,72 & $16.840,00$ & 3,86 & 0,73 \\
\hline Jerez & Trebujena & Señorío & $1.938,00$ & 0,53 & 0,1 & $1.720,00$ & 0,53 & 0,1 & $2.293,00$ & 0,53 & 0,1 \\
\hline Jerez & Alventos $^{138}$ & Señorío & 778,00 & 0,21 & 0,04 & 690,00 & 0,21 & 0,04 & 920,00 & 0,21 & 0,04 \\
\hline
\end{tabular}

135. Actual Carrión de los Céspedes (provincia de Sevilla).

136. Albaida del Aljarafe (provincia de Sevilla).

137. Despoblado del término municipal de Pilas (provincia de Sevilla).

138. Perteneciente al actual término municipal de Trebujena (provincia de Cádiz). 


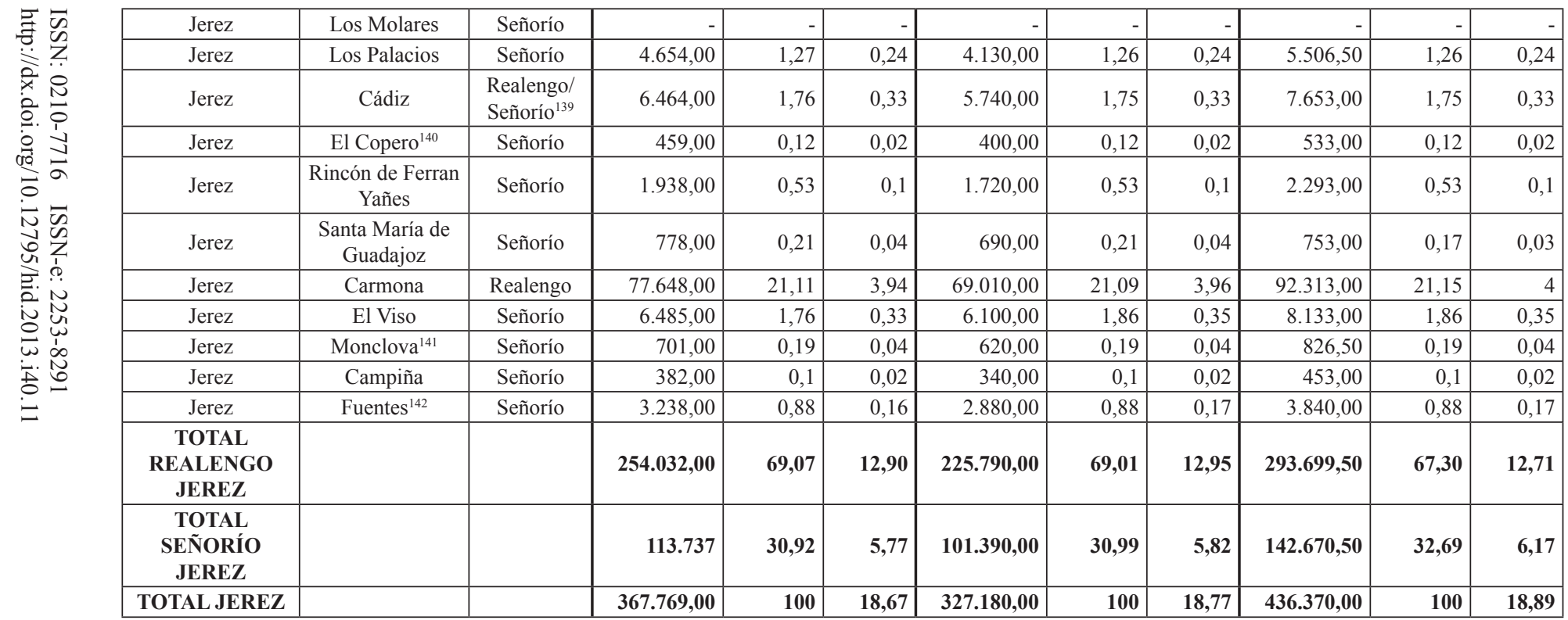

139. La plaza de Cádiz pasó por una etapa de dominio señorial (1466-1493) antes de volver al realengo, tal y como hemos explicado en el artículo.

140. Actualmente parte del término municipal de Dos Hermanas (provincia de Sevilla).

141. Despoblado de Fuentes de Andalucía (provincia de Sevilla).

142. Fuentes de Andalucía (provincia de Sevilla). 


\begin{tabular}{|c|c|c|c|c|c|c|c|c|c|c|c|}
\hline Niebla & $\begin{array}{c}\text { Villa de Niebla y } \\
\text { los lugares de su } \\
\text { condado }{ }^{143}\end{array}$ & Señorío & $58.589,00$ & 24,62 & 2,97 & $51.760,00$ & 24,44 & 2,97 & $69.003,00$ & 24,53 & 2,99 \\
\hline Niebla & $\begin{array}{c}\text { Gibraleón y su } \\
\text { tierra }\end{array}$ & Señorío & $23.794,00$ & 10 & 1,21 & $19.550,00$ & 9,23 & 1,12 & $26.090,00$ & 9,27 & 1,13 \\
\hline Niebla & Lepe & Señorío & $23.295,00$ & 9,79 & 1,18 & $20.700,00$ & 9,82 & 1,19 & $26.600,00$ & 9,45 & 1,15 \\
\hline Niebla & Ayamonte & Señorío & $1.938,00$ & 0,81 & 0,1 & $1.720,00$ & 0,81 & 0,1 & $2.293,00$ & 0,82 & 0,1 \\
\hline Niebla & La Redondela & Señorío & 905,00 & 0,38 & 0,05 & 800,00 & 0,38 & 0,05 & $1.066,50$ & 0,38 & 0,05 \\
\hline Niebla & Huelva & Señorío & $18.186,00$ & 7,64 & 0,92 & $18.430,00$ & 8,66 & 1,05 & $24.563,00$ & 8,73 & 1,06 \\
\hline Niebla & Moguer & Señorío & $38.925,00$ & 16,36 & 1,98 & $34.510,00$ & 16,3 & 1,98 & $46.013,00$ & 16,36 & 1,99 \\
\hline Niebla & Almonte & Señorío & $17.212,00$ & 7,23 & 0,87 & $15.300,00$ & 7,23 & 0,88 & $20.400,00$ & 7,25 & 0,88 \\
\hline Niebla & Bollullos ${ }^{144}$ & Señorío & $12.418,00$ & 5,22 & 0,63 & $11.040,00$ & 5,21 & 0,63 & $14.720,00$ & 5,23 & 0,64 \\
\hline Niebla & La Palma & Señorío & $23.295,00$ & 9,79 & 1,18 & $20.700,00$ & 9,78 & 1,19 & $27.600,00$ & 9,81 & 1,19 \\
\hline Niebla & Villalba & Señorío & $19.405,00$ & 8,15 & 0,99 & $17.240,00$ & 8,14 & 0,99 & $22.987,00$ & 8,17 & 1 \\
\hline $\begin{array}{c}\text { TOTAL } \\
\text { REALENGO } \\
\text { NIEBLA } \\
\end{array}$ & & & 0,00 & 0 & 0 & 0,00 & 0 & 0 & 0,00 & 0 & 0 \\
\hline $\begin{array}{l}\text { TOTAL } \\
\text { SEÑORÍO } \\
\text { NIEBLA }\end{array}$ & & & $237.962,00$ & 100 & 12,08 & $211.750,00$ & 100 & 12,15 & $281.335,50$ & 100 & 12,18 \\
\hline TOTAL NIEBLA & & & $237.962,00$ & 100 & 12,08 & $211.750,00$ & 100 & 12,15 & $281.335,50$ & 100 & 12,18 \\
\hline Écija & Écija & Realengo & $116.471,00$ & 54,10 & 5,91 & $103.530,00$ & |56,47 & 5,94 & $126.929,00$ & 54,4 & 5,50 \\
\hline Écija & Marchena & Señorío & $49.000,00$ & 22,76 & 2,49 & $39.110,00$ & 21,33 & 2,24 & $52.147,00$ & 22,35 & 2,26 \\
\hline Écija & Mairena $^{145}$ & Señorío & $11.641,00$ & 5,41 & 0,59 & $10.340,00$ & 5,64 & 0,59 & $13.786,50$ & 5,91 & 0,60 \\
\hline
\end{tabular}

143. Los citados por la documentación aquí utilizada son Torrecilla, Facanias, Calañas, Alquería de Juan Pérez, Vegas, Beas, Trigueros, Lucena, El Portezuelo, Rociana y Callejón y sus lugares.

144. Bollullos del Condado (provincia de Huelva).

145. Mairena del Alcor (provincia de Sevilla). 


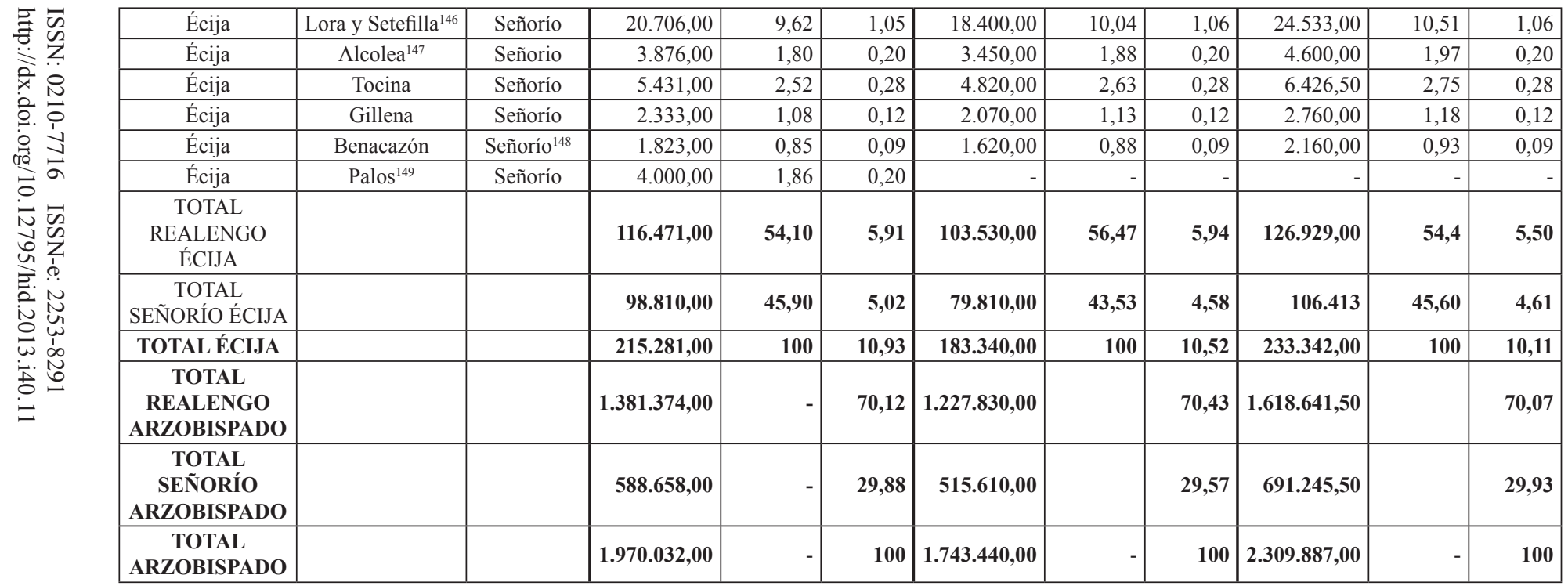

146. Setefilla es actualmente un despoblado perteneciente al término municipal de Lora (provincia de Sevilla).

147. Alcolea del Río (provincia de Sevilla).

148. Pese a aparecer como lugar de señorío en la documentación del siglo XV, Benacazón nunca contó con privilegio o merced real que confirmara esta situación, M. BORRERO FERNÁNDEZ, El mundo rural ... p. 49.

149. El único año en el que tenemos referencias a Palos, de los que conservamos para el siglo XV, es en este de 1411. 


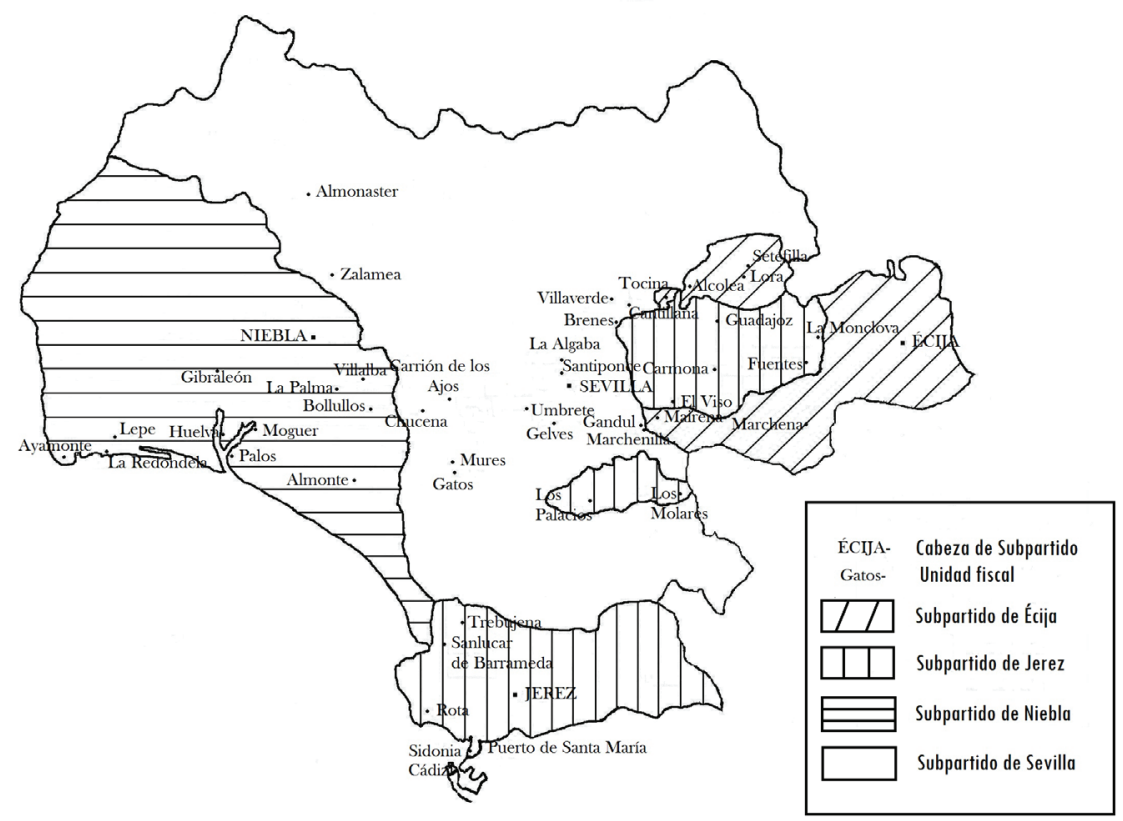

Partido del Arzobispado de Sevilla y el Obispado de Cádiz

\section{BIBLIOGRAFÍA}

Cortes de los antiguos reinos de León y de Castilla tomo III, Real Academia de la Historia, Madrid, 1866.

Colección de privilegios, franquezas, exenciones y fueros concedidos a varios pueblos y corporaciones de la corona de Castilla, copiados de orden de S. M. de los registros del Real Archivo de Simancas, Imprenta Real, Madrid, 1830.

AGUADO GONZÁLEZ, F.J. "Fuentes para el estudio de la geografía administrativa y la distribución de la población de la Corona de Castilla en la segunda mitad del siglo XV: las relaciones de pueblos para el cobro del pedido", Аnиario de Estudios Medievales, $\mathrm{n}^{\circ} 16$ (1986), pp. 465-480.

ALONSO GARCÍA, D. "Crear espacios, cobrar impuestos. Los partidos fiscales de Castilla a principios de la Edad Moderna" en SALAS ALMELA, L. Los ámbitos de la fiscalidad: fronteras, territorios y percepción de tributos en los Imperios ibéricos (siglos XV-XVIII), Instituto de Estudios Fiscales y Universidad de Málaga, Madrid, 2011.

ANASAGASTI VALDERRAMA, A.M. y RODRÍGUEZ LIÁÑEZ, L. Niebla y su tierra en la Baja Edad Media: historia y documentos. Diputación de Huelva, Huelva, 2006. 
BORRERO FERNÁNDEZ, M. El mundo rural sevillano en el siglo XV: Aljarafe y Ribera. Diputación provincial de Sevilla, Sevilla, 1983.

—. "Situación demográfica de la Sierra Norte de Sevilla (siglo XV-1534)", Historia, instituciones, documentos, $\mathrm{n}^{\circ} 25,1998$, pp. 43-72.

CARANDE Y THOVAR, R. Sevilla, fortaleza y mercado: las tierras, las gentes y la administración de la ciudad en el siglo XIV, Diputación provincial de Sevilla, Sevilla, 1982.

-, CARRIAZO RUBIO, J. DE LA M. El tumbo de los Reyes Católicos en el Concejo de Sevilla, tomo II (años 1477-1479), Universidad de Sevilla, Sevilla, 1968.

CARRETERO ZAMORA, J.M. La averiguación de la Corona de Castillla (15251540). Los pecheros y el dinero del reino en la época de Carlos $V$, Junta de Castilla y León, Salamanca, 2008.

COLLANTES DE TERÁN SÁNCHEZ, A. Sevilla en la Baja Edad Media. La ciudad y sus hombres, Ayuntamiento de Sevilla, Sevilla, 1977.

—. "Los señoríos andaluces. Análisis de su evolución territorial en la Edad Media", Historia, instituciones, documentos, n6 (1979), pp. 89-112.

- . "Un informe sobre la confección de los padrones de cuantía", Historia, instituciones, documentos, $\mathrm{n}^{\circ} 19$ (1992), pp. 149-160.

—. "Las ciudades andaluzas en la transición de la Edad Media a la Moderna", Minervae Baeticae. Boletín de la Real Academia Sevillana de Buenas Letras, 32 (2004), pp. 30-124.

FLORES VARELA, C. Estudio demográfico de la Andalucía cristiana, 14001535, Tesis doctoral dirigida por Cristina Segura Graiño, Universidad Complutense de Madrid, 2001.

FRANCO SILVA, A. "La villa de Marchena en la Baja Edad Media. Linaje, rentas, posesiones y ordenanzas", en Actas de las II Jornadas de Historia de Marchena, Marchena, 1997, 309-344.

GARCÍA-ARRECIADO BANATERO, MaA. "La villa de Huelva en la Baja Edad Media", Huelva en su Historia, vol. 2 (1988), pp. 175-230.

GONZÁLEZ GÓMEZ, A. Moguer en la Baja Edad Media, Instituto de Estudios Onubenses, Huelva, 1977, pp. 55-70.

GONZÁLEZ JIMÉNEZ, M. "La Baja Andalucía a fines del medievo", Arquipélago. Revista da Universidade dos Açores. Serie Historia. Vol XI (1989), pp. 9-48.

—. "Écija, señorío de los príncipes de Asturias (siglo XV)", en Écija en la Edad Media y el Renacimiento, Universidad de Sevilla, 1993, pp. 53-66.

HERRERA GARCÍA, A. El Aljarafe sevillano durante el Antiguo Régimen: un estudio de su evolución socioeconómica, Diputación de Sevilla, Sevilla, 1980.

-. "Noticias, documentos y vicisitudes de los señoríos de Castilleja de Talhara, despoblado del Aljarafe", Hidalguía, XXVI, n 146, pp. 65-88.

IGLESIAS RODRÍGUEZ, J.J. El Puerto de Santa María, Diputación Provincial de Cádiz, Cádiz, 1985. 
LADERO QUESADA, M.Á. “Los señoríos medievales en el ámbito de Cádiz y Jerez de la Frontera", En la España Medieval, no 2 (1982), pp. 543-572.

-. Historia de Sevilla. La ciudad medieval (1248-1492), Universidad de Sevilla, Sevilla, 1989.

- Niebla, de reino a condado. Noticias del Algarbe andaluz en la Baja Edad Media, Real Academia de Historia, Madrid, 1992.

- . "Las regiones históricas y su articulación política en la Corona de Castilla durante la Baja Edad Media", En la España Medieval, n¹5 (1992), pp. 213-247.

—. "Los señoríos medievales onubenses. Período de formación", en CARRIAZO RUBIO, J. DE LA M. y MIURA ANDRADES, J.M (coord.). Huelva en la Edad Media: reflexiones, aportaciones y nuevas perspectivas veinte años después, Universidad de Huelva, Huelva, 1998, pp. 203-228.

-. La Hacienda Real de Castilla (1369-1504). Real Academia de la Historia, Madrid, 2009.

MORENO OLLERO, A. Sanlúcar de Barrameda a fines de la Edad Media, Diputación Provincial de Cádiz, Cádiz, 1983.

MARTÍN GUTIÉRREZ, E. La identidad rural de Jerez de la Frontera. Territorio y poblamiento durante la Baja Edad Media, Publicaciones de la Universidad de Cádiz, Cádiz, 2003.

MONTES ROMERO-CAMACHO, I. "Sevilla y la frontera de Granada durante el reinado de Enrique IV (1454-1474)", en SEGURA GRAIÑO, C. Relaciones exteriores del Reino de Granada, Coloquio de Historia Medieval andaluza, Instituto de Estudios Almerienses, Almería, 1988, pp. 123-145.

NAVARRO DOMÍNGUEZ, J.M. "Expansión económica en la Baja Andalucía en el siglo XVI. El modelo de la ciudad de Écija", en Écija en la Edad Media y el Renacimiento, Universidad de Sevilla, 1993.

NAVARRO SAÍNZ, J.Ma . "La subordinación política de la tierra de Sevilla al concejo hispalense en el reinado de Isabel I", Historia, instituciones, documentos, no 38 (2011), pp. 325-360.

OLIVERA SERRANO, C. Las Cortes de Castilla y León y la crisis del reino. El registro de Cortes, Cortes de Castilla y León, Burgos, 1986.

_. "Pedidos y monedas en Valladolid y su infantado a mediados del siglo XV", en Valladolid: historia de una ciudad. Congreso internacional. Tomo I: La ciudad medieval y el arte, Ayuntamiento de Valladolid, Valladolid, 1999, pp. 315-326.

—. "El pedido de 1455 en el reino de Galicia", Cuaderno de Estudios Gallegos, tomo LI, fascículo 117 (2004), pp. 366-374.

PÉREZ-EMBID WAMBA, J. "Las sierras de Aroche y Aracena: la formación de una unidad comarcal en el reino de Sevilla durante la Baja Edad Media", en CARRIAZO RUBIO, J.L. y MIURA ANDRADES, J.M (coord.). Huelva en la Edad Media 20 años después, Universidad de Huelva, Huelva (1998), pp. 109-144.

RODRÍGUEZ SARRIA, J. “¿Cobrar para el rey? Los pedidos regios: procedimientos y agentes de la recaudación en la Sevilla del siglo XV" en GALÁN SÁNCHEZ, Á. Y GARCÍA FERNÁNDEZ, E. (eds.) En busca de Zaqueo: los 
recaudadores de impuestos en las épocas medieval y moderna. Instituto de Estudios Fiscales, Madrid (2012), pp. 79-98.

ROMERO ROMERO, F.J. Sevilla y los pedidos de Cortes en el siglo XV, Ayuntamiento de Sevilla, Sevilla, 1997.

RUBIO MARTÍNEZ, A. "Los ingresos extraordinarios del reino de Galicia en el siglo XV", Cuadernos de Estudios Gallegos, tomo 57, $\mathrm{n}^{\circ} 123$ (2010), pp. 229-271.

Fecha de recepción del artículo: septiembre 2013

Fecha de aceptación y versión final: octubre 2013 
